\title{
Contribution to Gas Production from Minor Coal Seams and Adjacent Shales: Numerical Modelling Results for the Mannville Coal Measures, South Central Alberta
}

\author{
Amanda M. M. Bustin, R. Marc Bustin \\ Department of Earth, Ocean and Atmospheric Sciences, The University of British Columbia, Vancouver, Canada \\ Email: abustin@eoas.ubc.ca
}

How to cite this paper: Bustin, A.M.M. and Bustin, R.M. (2019) Contribution to Gas Production from Minor Coal Seams and Adjacent Shales: Numerical Modelling Results for the Mannville Coal Measures, South Central Alberta. International Journal of Geosciences, 10, 758-783.

https://doi.org/10.4236/ijg.2019.107043

Received: May 28, 2019

Accepted: July 28, 2019

Published: July 31, 2019

Copyright $\odot 2019$ by author(s) and Scientific Research Publishing Inc. This work is licensed under the Creative Commons Attribution International License (CC BY 4.0).

http://creativecommons.org/licenses/by/4.0/

\begin{abstract}
The contribution to production of the gas stored within the coal and shale beds adjacent to the main coal seam in the Mannville Group, in which a lateral is drilled, was investigated through a series of numerical simulations. The results indicate that the added gas from the minor coal seams, with interbedded shales with no gas, results in 1.4 times $(x)$ more produced gas and 3.0 $x$ more produced water after 25 years of production than when only the main Mannville coal seam is considered. Including gas in the shales results in $1.7 \times$ more produced gas and $2.5 \times$ more produced water after 25 years of production than when only the main coal seam is considered. The produced gas recovered from the shales exceeds the produced gas recovered from the coals after $\sim 8.5$ years, resulting in $2.1 \times$ more produced shale gas than coal gas after 25 years of production. Over half $(56 \%)$ of the produced coal gas after 25 years of production is recovered from the main coal seam while a quarter (22\%) is recovered from the L1 seam, which is the thickest and nearest minor coal seam to the horizontal wellbore located in the main seam. The results from the numerical simulations provide insights that are not intuitive or otherwise predictable in developing complex reservoirs. Although the results are specifically for the Mannville producing fairway, undoubtedly the production from minor coal seams and interbedded gas shales should be considered in other producing and potential coal gas reservoirs to identify higher producible reserves and optimize drilling and completions strategies.
\end{abstract}

\section{Keywords}

Coalbed Methane, Gas Shales, Reservoir Modelling, Comingled Production 


\section{Introduction}

The main coalbed methane target in the Mannville Group of the Western Canadian Sedimentary Basin in south-central Alberta is the thickest coal seam in the Upper Mannville (Figure 1(a) and Figure 1(b)), which has an average thickness of $2.9 \mathrm{~m}$ (range 1.3 - $4.5 \mathrm{~m}$; Figure 1(c)). Two to three additional coal seams; however, are generally present both above and below the main coal seam (Figure 1(d)), giving an average net coal thickness of $\sim 6.8 \mathrm{~m}(3.8-8.2 \mathrm{~m})$. Reference [1] showed that $36 \%$ of the total calculated gas-in-place in the Upper Mannville coal measures (average of $5.9 \mathrm{BCF} / \mathrm{mi}^{2}$ ) is contained within the minor coal seams (Figure 1(e)). Significant gas is also stored within the high organic content, fine-grained strata (referred to here as gas shales) interbedded as well as over- and under-lying the coal seams (Figure 1(d)). Including the gas shales in resource assessment, increases the potential net pay to $\sim 50 \mathrm{~m}$ or even greater when the shales over- and under-lying the coal seams are included. Assuming a $\pm 20 \mathrm{~m}$ stratigraphic interval around the main seam [2], calculated that including the shales increases the average total gas-in-place in the Upper Mannville Group $1.7 \times\left(10.2 \mathrm{BCF} / \mathrm{mi}^{2}\right.$ vs $5.9 \mathrm{BCF} / \mathrm{mi}^{2}$; Figure $\left.1(\mathrm{f})\right)$.

The purpose of this study is to determine the producibility of the minor coal seams and interbedded gas shales, which are generally not considered in the total gas-in-place calculations or in field development (as discussed in [1] [2]). In field development to date in the producing Mannville fairway, the contribution of the minor coals and adjacent and interbedded gas shales to production have not been considered. The relative contribution of coals, other than the main coal seam in which the lateral is drilled and completed (Figure 1(d)), and adjacent shales, is difficult to quantify and predict. Hence numerical simulations provide one of the only methods in which predictions can be made on which to base spacing units, well design, and completions strategies.

The economic potential of unconventional gas reservoirs is determined by both the total amount of gas in the reservoir as well as the producibility of that gas. The total amount of gas depends on the adsorption capacity, porosity, density, saturation, thickness, lateral extent, and reservoir pressure and temperature. The producibility is determined in significant part by the fabric of the rock, which includes both the microfabric of the matrix, controlling the rate of gas transport through the matrix, and the fracture network, controlling both the path length for gas transport through the matrix as well as the fracture permeability. The production potential of the coal and shale layers is most sensitive to fracture permeability, which depends on the fracture spacing, fracture aperture, and relative fluid saturation.

In this study, experimental and field data from the Mannville coal measures and adjacent shales in the Corbett region in south-central Alberta are used as model inputs for a general equation-of-state reservoir simulator (CMG-GEM). Numerical simulations from CMG-GEM have previously been used for predicting the producibility of unconventional gas reservoirs (ex. [3]-[8]) including the 
(a)

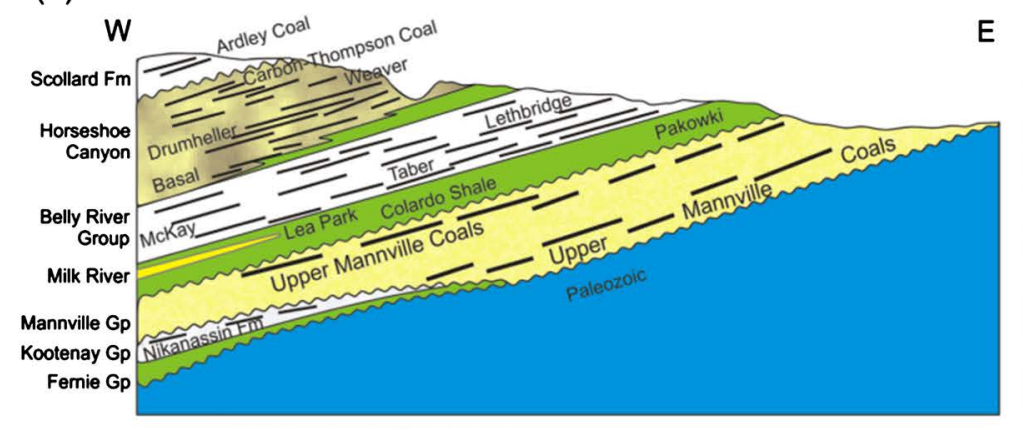

$\mathrm{E}$

(d)

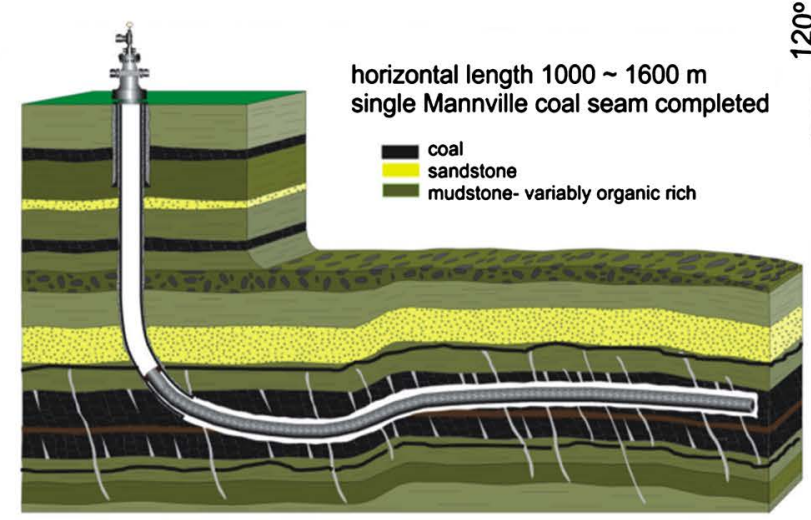

(b)

(c)

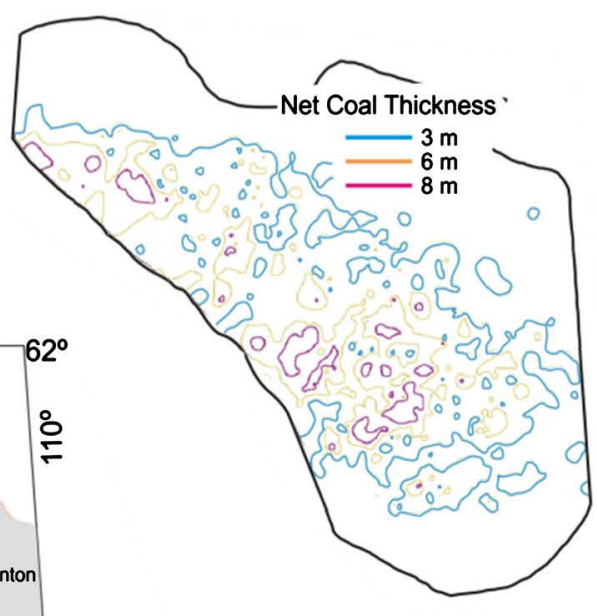

(e)

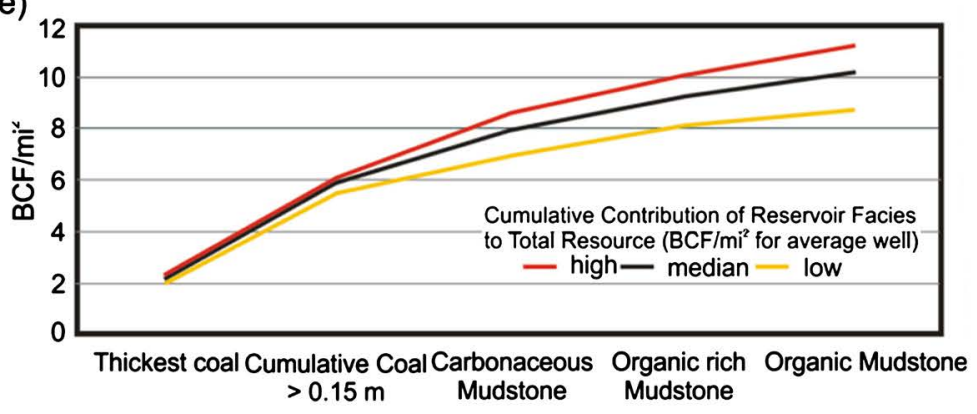

(f)

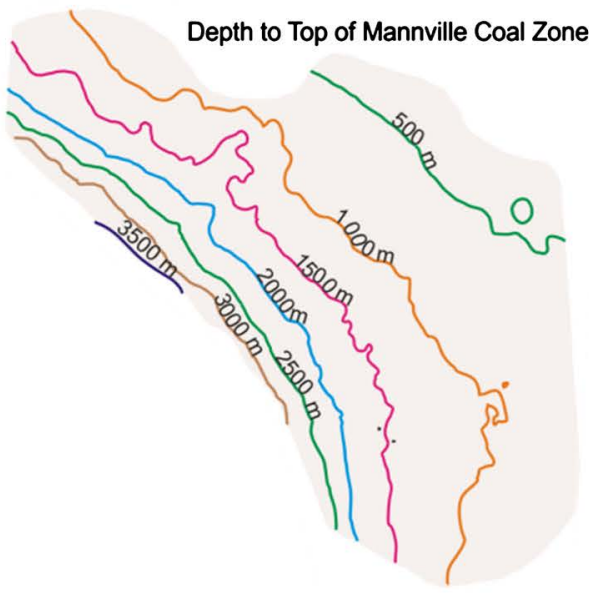

Figure 1. (a) Schematic cross-section across the Western Canadian Sedimentary Basin (modified from [10]). (b) Mannville coal distributions in Alberta shown as the grey region and the location of the Corbett fairway is shown as the red rectangle (modified from [11]). (c) Net thickness of the main (i.e. thickest) Mannville coal seam in the Corbett fairway (modified from [11]). (d) Schematic diagram of a single horizontal well drilled and completed in the main Mannville coal seam in the sequence (modified from [12]). (e) Cumulative resource by BCF/section for the P10 (low), P50 (median), and P90 (high) gas contents showing the contributions of the main coal seam, all coal seams $>0.15 \mathrm{~m}$, and the shales (variably organic mudstones) for the Mannville coal measures (modified from [2]). (f) Depth to the top of the main Mannville coal seam in the Corbett fairway (modified from [13]).

main Upper Mannville coal seam [9]. The modelling in this study, for the first time, addresses the extent to which the gas stored within adjacent shales and coals is produced from a horizontal well through the main (i.e. thickest) coal seam in a wet reservoir. The commingled production of shales when the coal seams are perforated in a vertical well within the dry Horseshoe Canyon and Belly River coal measures was previously investigated using CMG-GEM [10]. 
Reference [10] found that including gas-bearing shales interbedded between coal seams increased the cumulative gas production by $144 \%$ after 50 years and resulted in reconsideration of optimum well spacing units.

\section{Geological Setting}

In earlier papers that quantify the gas in place in the coals and shales of the Mannville coal measures, we summarise the stratigraphy, structural setting, tectonic history, and coalbed methane development ([1] [2]). Below we provide a review of the salient points as pertains to this paper.

The stratigraphy and sedimentology of the Mannville Group have been extensively studied to determine the economic importance of the petroleum and coal resources. The Lower Cretaceous (Aptian to mid Albian) Mannville Group is a sequence of marine, transitional marine, and non-marine sediments sourced from the Western Canadian cordillera to the west and deposited in an asymmetric basin (e.g. [14]). The Mannville Group ranges markedly in thickness from 40 $\mathrm{m}$ in the east on the stable platform to over $700 \mathrm{~m}$ in the west in the Rocky Mountain foothills, due to both deposition and subsequent erosion. Coal occurs in the Lower and Upper Mannville Group, but the main coal zone exploited for coalbed methane production is restricted to the undifferentiated Upper Mannville Group. The depth to the top of the main coal zone varies from a few tens of meters in the eastern part of the basin to greater than $3500 \mathrm{~m}$ in the Rocky Mountain Foothills (Figure 1(f)). Cumulative coal thickness is from 0 to $16.5 \mathrm{~m}$ and includes seams as thick as $12 \mathrm{~m}$ [15]. The gas-in-place ranges from about 50 to $350 \mathrm{scf} /$ ton $\left(2-10 \mathrm{BCF}^{1} / \mathrm{mile}^{2}\right)$ and is closely correlated with depth of burial and coal rank. The Mannville coalbed methane resource occurs over a very large geographic area of southern and central Alberta and in equivalent strata in British Columbia. The total estimated coal gas resource in place is about $325 \mathrm{TCF}^{2}$ in the Mannville Formation [16]. Numerous comprehensive studies have been undertaken by the Alberta Geological Survey, including regional subsurface mapping that includes isopach maps, coal rank, and estimated coal gas content [17] [18] [19]. Local studies of coalbed methane potential and production include articles by [15] [20] [21] [22] [23].

Exploration for coalbed methane in the Upper Mannville Group commenced in the mid-1990s and to date about 1 TCF $\left(28.3 \times 10^{9} \mathrm{~m}^{3}\right)$ of gas has been produced. The first commercial horizontal coalbed methane well began producing in 2004, averaging $1 \mathrm{mmcf} / \mathrm{d}\left(28.3 \times 10^{3} \mathrm{~m}^{3}\right)$ during the first four years of production [20]. Production in 2016 was about $800 \mathrm{mmcf} /$ day, almost all of which is from a fairway of wet coals $(\mathrm{Sw}>0)$ about $4000 \mathrm{~km}^{2}$ in central Alberta' referred to as Corbett (Figure 1(b)). In the Corbett area, coal gas is produced from about 200 multilateral horizontal wells, spaced mainly at $3-4$ wells per mile ${ }^{2}(2.59$ $\mathrm{km}^{2}$ ). The horizontal wells are completed mainly in the thickest seam in the succession and are orientated NW-SE, N-S, and E-W with the horizontal legs be${ }^{1}$ billion cubic feet $\left(2.83 \mathrm{E} 7 \mathrm{~m}^{3}\right)$.

${ }^{2} 1$ trillion cubic feet $\left(2.83 \mathrm{E} 10 \mathrm{~m}^{3}\right)$. 
tween 1000 and $1500 \mathrm{~m}$ in length. Outside the Corbett fairway, commercial production rates have rarely been achieved irrespective of the drilling and completion strategies employed.

The Mannville coal measures, like most coal measures in the World, commonly include multiple coal seams or zones and are commonly interbedded with and/or are overlain by organic-rich fine-grained strata. In areas where horizontal wells are used, the laterals are located in the thickest seams as a matter of practise. Thin adjacent seams and other organic rich lithologies can reasonably be expected to contribute to the gas resource and provide producible gas to the main lateral. The contribution of organic-rich shales and other coals to production, although possibly intuitive to some, is difficult to quantify. Numerical modeling, such as described in this paper, provides insights as to the producible coal and other lithologies and is thus powerful for reserve analysis and for optimising well spacing units, lateral lengths, and orientations.

\section{Model Parameters}

The model parameters for this study were compiled from existing industry and academic databases as well as from our new laboratory tests on coal and shale samples collected from three Mannville wells: 12-31-62-05W5, 15-27-62-06W5, and 16-10-62-06W5 [1] [2] [24]. The production was simulated from a single $1000 \mathrm{~m}$ long horizontal well centered within a $6400 \times 6400 \mathrm{~m}$ model, discretized into $100 \mathrm{~m}$ grid blocks. The horizontal well is oriented within the model perpendicular to the direction of the maximum coal fracture permeability, which is assumed to be anisotropic. Production from Mannville coals indicates a directional component of system permeability, with permeability $2-3$ times $(x)$ higher in the direction $\mathrm{N} 25^{\circ} \mathrm{E}$, which is parallel to a developed face cleat. The coal permeability was thus input as three times higher in one horizontal direction than the other horizontal direction (at $90^{\circ}$ ) and the vertical direction (Figure 2). To account for the commonly observed transversely isotropic intrinsic shale symmetry, the shale fracture permeability was assumed to be an order of magnitude higher in the horizontal than the vertical direction in the absence of field measurements (Figure 2). The fracture permeabilities were held constant during the modelling; however, the impact of dynamic changes in permeability with effective stress was investigated by [24]. The produced water from the Mannville coals indicates that any contribution due to free gas within the porosity of the coal matrix would be minor and hence free gas was not considered in the models.

The depth and thickness of the horizontally stacked coal seams in the models, determined from interpretations of logs from well 16-10-62-06W5, are shown in Table 1. Layers (beds) of gas shales were interbedded with the coal layers, with thickness varying from $1.1 \mathrm{~m}$ to $20 \mathrm{~m}$. Shale layers $20 \mathrm{~m}$ thick were also added for $200 \mathrm{~m}$ above and $400 \mathrm{~m}$ below the reservoir, resulting in a model extending from 745 to $1415 \mathrm{~m}$ in depth. A cross-section of the model showing the geometry of the coal versus shale layers is shown in Figure 2. 


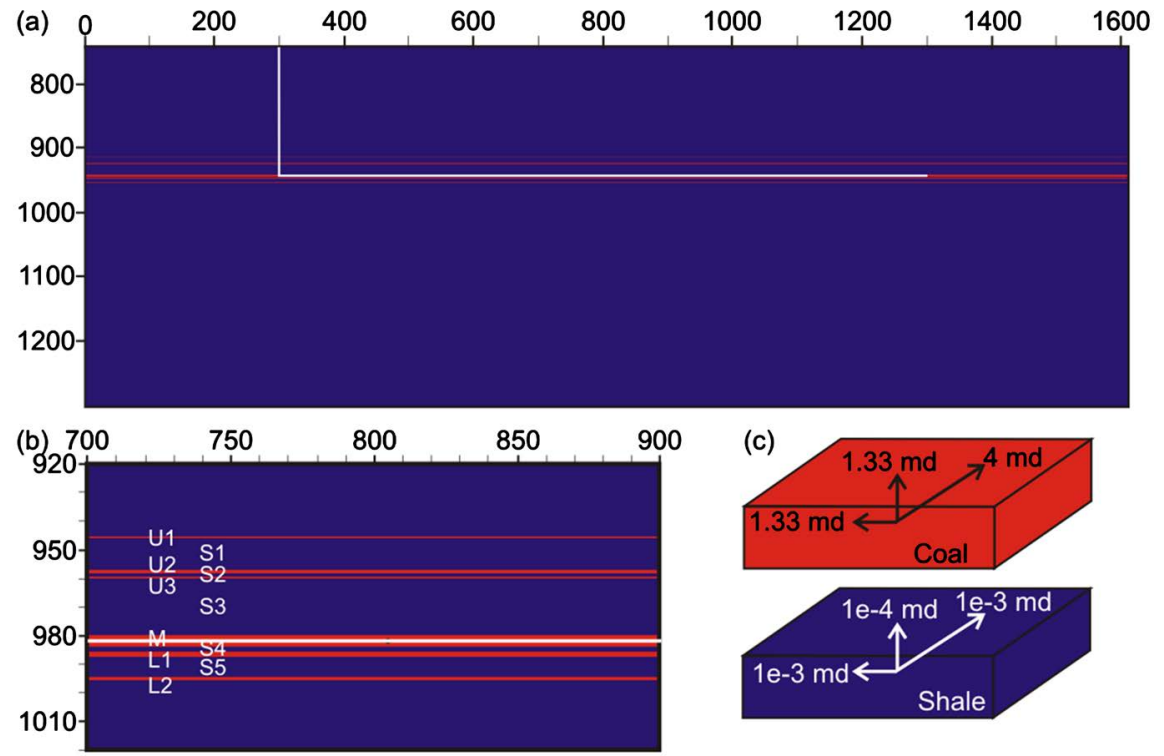

Figure 2. ((a) and (b)) Cross-section of the model through a plane containing the wellbore showing the geometry of the coal seams (red) versus shale layers (blue). (a) Cross-sectional view of the full model and (b) close-up of the reservoir. The labels for the coal seams and interbedded shale layers are shown in (b). The location of the horizontal well is shown by thin white lines. (c) Three-dimensional schematic illustrating the coal (top) and shale (bottom) fracture permeability anisotropy.

Table 1. Depth to top of coal seams and seam thickness for the three models.

\begin{tabular}{ccc}
\hline \multirow{2}{*}{ Coal Seam } & \multicolumn{2}{c}{ 16-10-62-6W5 } \\
\cline { 2 - 3 } & Depth $(\mathrm{m})$ & Thick $(\mathrm{m})$ \\
\hline U1 & 945.3 & 0.9 \\
U2 & 957.5 & 0.7 \\
U3 & 959.3 & 0.7 \\
M & 980.0 & 4.0 \\
L1 & 986.0 & 1.8 \\
L2 & 994.6 & 1.0 \\
\hline
\end{tabular}

Estimates of the parameter values for each lithologic unit are not available and since accurate production forecasting and history matching are not the goals of the modelling, the model parameters were averaged such that each coal layer, while having unique geometry, is assigned equal parameter values. All the shale layers were also assigned equal parameter values, which were chosen from the statistics of measured values from all shales [1] [2] [24]. When appropriate, probability distributions were calculated for the parameter values by first fitting a normal distribution to each dataset and then performing a Monte Carlo simulation. The average values were thus chosen as the $50 \%$ probability (P50). Insufficient data exists for the Langmuir parameters for the shales $(n<15)$, in these cases simple arithmetic averages were calculated. A more complete description of the model parameters as well as an investigation into their impact on produc- 
tion is presented in [24]. The average parameter values used as inputs during the simulations as well as the number of data points available for each parameter are tabulated in Table 2.

\section{Results}

The reservoir modelling in this study was carried out using the commercial CMG's GEM advanced general equation-of-state compositional simulator, which is a dual porosity, dual permeability model with gas phase diffusion. The impact of gas-bearing adjacent shales and coals to the production from a horizontal well through the main Mannville coal seam is investigated by comparing the results from three models. The simulation results for a model containing only the thickest Mannville coal seam, in which the lateral is normally drilled and completed (main-only model), with the average parameters listed in Table 2 , are first discussed, followed by the results for a model with the additional gas-bearing mi nor coal seams with average parameters as well as inter-bedded and over- and under-lying shale layers with no adsorbed gas (no-shale-gas model, all other parameters are the average values listed in Table 2). The results for the main-only model and the no-shale-gas model are compared and then the results for a model with gas-bearing shale layers in addition to the gas-bearing

Table 2. The input parameters used during the modelling.

\begin{tabular}{|c|c|c|c|c|c|c|}
\hline \multirow{2}{*}{ Parameter } & \multicolumn{2}{|c|}{ Reservoir } & \multicolumn{2}{|c|}{ Coal } & \multicolumn{2}{|c|}{ Shale } \\
\hline & $\mathrm{n}$ & Ave & $\mathrm{n}$ & Ave & $\mathrm{n}$ & Ave \\
\hline Temperature, ${ }^{\circ} \mathrm{C}$ & 130 & 42 & & & & \\
\hline Pressure gradient, $\mathrm{kPa} / \mathrm{m}$ & 279 & 8.2 & & & & \\
\hline Water Saturation, \% & & 99 & & & & \\
\hline Critical water saturation, $\%$ & & 60 & & & & \\
\hline Bottom hole pressure, $\mathrm{kPa}$ & & 200 & & & & \\
\hline Density, g/cc & & & 354 & 1.4 & 35 & 2.2 \\
\hline Langmuir volume, $\mathrm{cc} / \mathrm{g}$ & & & 45 & 13.7 & 12 & 1.5 \\
\hline Langmuir pressures, $\mathrm{MPa}$ & & & 45 & 5.7 & 12 & 6.2 \\
\hline Matrix permeabililty, md & & & 3 & $1 e-3$ & & $1 e-5$ \\
\hline Diffusion, $\mathrm{cm}^{2} / \mathrm{s}$ & & & & 0.05 & & $8 e-3$ \\
\hline Matrix porosity ${ }^{\mathrm{a}}, \%$ & & & & $1 \mathrm{e}-4$ & & $1 \mathrm{e}-4$ \\
\hline Effective fracture spacing, $\mathrm{m}$ & & & & 0.5 & & 10 \\
\hline Max horiz fracture perm, md & & & 110 & 3.8 & & $1 e-3$ \\
\hline Min horiz fracture perm, md & & & & $=\mathrm{k}_{\max } / 3$ & & $=\mathrm{k}_{\max }$ \\
\hline Vert fracture perm, md & & & & $=\mathrm{k}_{\max } / 3$ & & $=\mathrm{k}_{\max } / 10$ \\
\hline Fracture porosity, $\%$ & & & & 0.01 & & $1 \mathrm{e}-4$ \\
\hline
\end{tabular}

a. Note that the matrix porosity values listed above were assumed during the modelling, due to the bound matrix water (matrix $S_{w}$ assumed to be zero by the model), and are not the measured values. 
coal layers (shale-gas model) are discussed and compared to the results for the main-only and no-shale-gas models.

\subsection{Model with Only the Main Mannville Coal Seam}

A Mannville coal seam, $4.0 \mathrm{~m}$ thick, with the average parameters values listed in Table 2, contains $1.78 \times 10^{9} \mathrm{~m}^{3}$ of gas stored by adsorption in the matrix and $1.63 \times 10^{4} \mathrm{~m}^{3}$ of water stored in the fractures over the $6400 \mathrm{~m} \times 6400 \mathrm{~m}$ model area. The gas and water production histories over 25 years, from a $1000 \mathrm{~m}$ long horizontal well centered in the main Mannville coal seam, for a model containing only the Mannville coal seam (main-only model) are shown in Figure 3 (pink curves). The simulation results indicate that at the end of the 25 year history, $2.56 \times 10^{8} \mathrm{~m}^{3}$ of gas is produced, while $5.30 \times 10^{3} \mathrm{~m}^{3}$ of water is produced from the model area.

The initial gas production rate steeply increases to an initial peak rate within the first hour of production (pink curve in Figure 3(b)), which is associated with a steep decrease in the initial water production rate (pink curve in Figure 3(d)). The initial water produced near the wellbore decreases the water saturation and hence increases the gas saturation (as shown in Figure 4), which decreases the

(a)

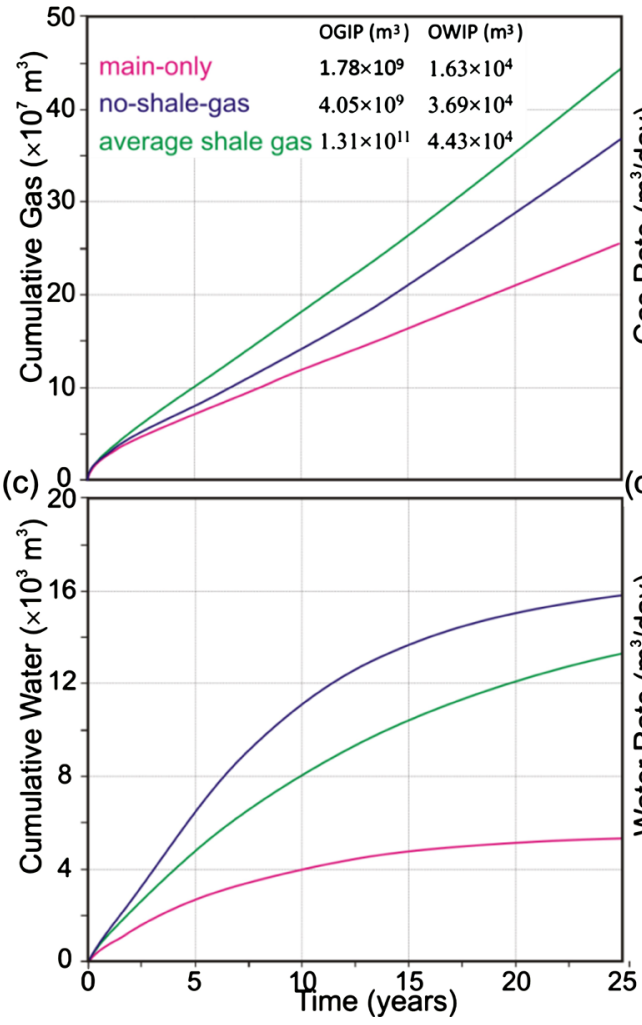

(b)

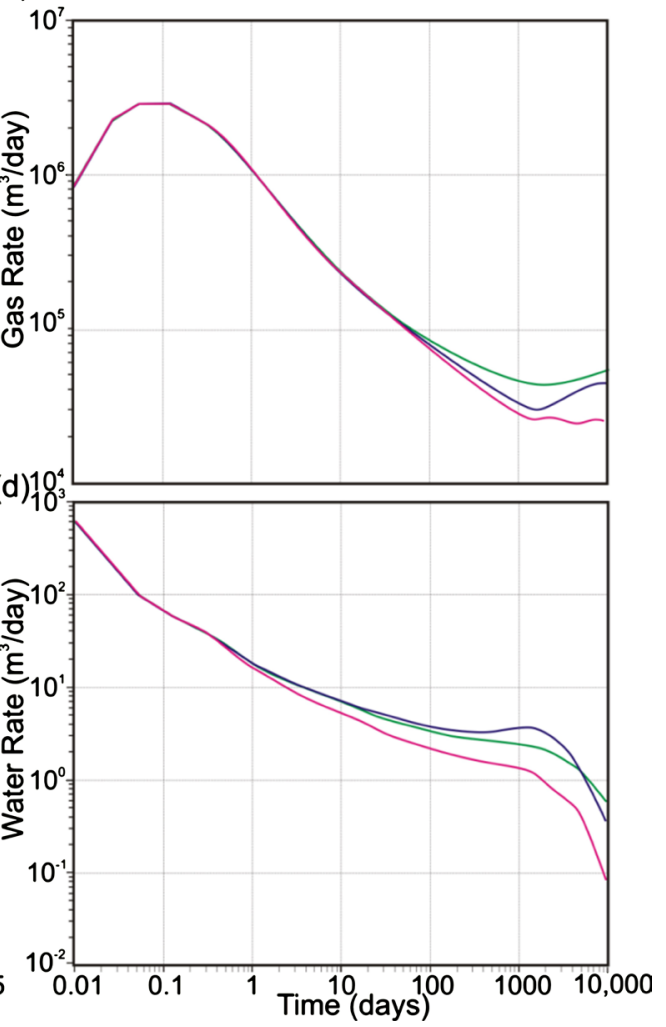

Figure 3. Comparison of the gas (top) and water (bottom) cumulative production (left) and production rates (right) simulated for a model with gas-bearing coal and shale layers with the average model parameters (average shale-gas model; green curves), a model with gas-bearing coal layers and shale layers with no gas (no-shale-gas model; blue curves), and a model with only the main Mannville coal seam (main-only model; pink curves). 


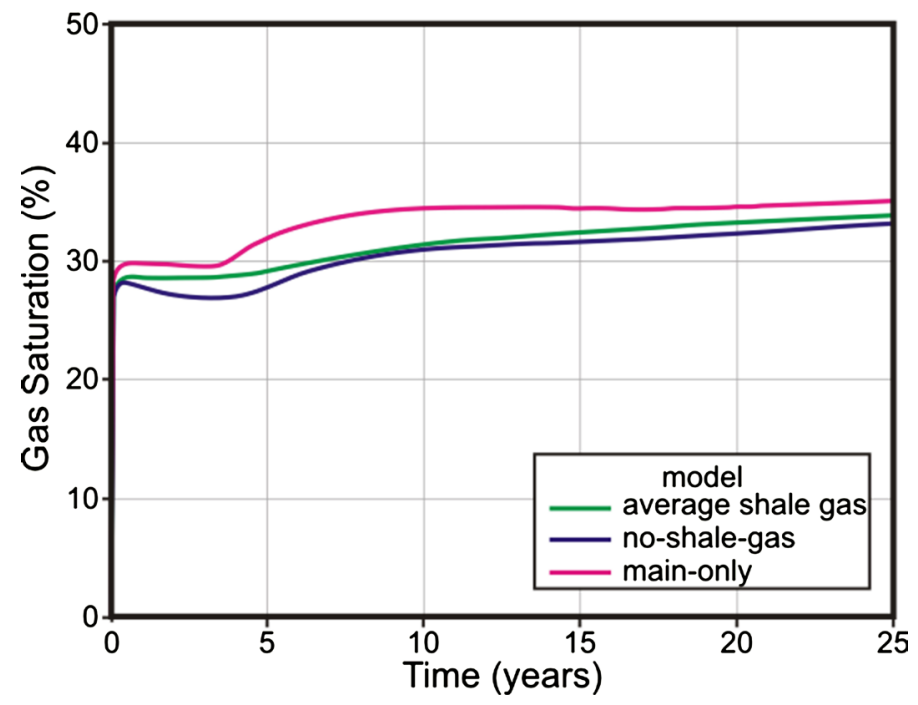

Figure 4. Comparison of the gas saturation at a point in the main Mannville coal seam $200 \mathrm{~m}$ perpendicular to the center of the horizontal wellbore for a model with the average coal and shale model parameters (average shale gas model; green curve), a model with no shale gas (no-shale-gas model; blue curve), and a model with only the main coal seam (main-coal only; pink curve).

relative fracture permeability to water and increases the relative fracture permeability to gas. Water farther from the wellbore travels along the coal seam towards the horizontal well, replenishing the water saturation and slowing the decline in the water production rate, decreasing the gas production rate after $\sim 3$ hrs of production. The gas production rate continues to decrease until after $\sim 4$ years (1490 days) of production when it begins increasing. The increase in gas production rate corresponds to when the water production rate begins to decrease, which depends on the volume of water stored and the relative permeability curves. The gas production rate reaches a peak of $2.65 \times 10^{4} \mathrm{~m}^{3} /$ day at $\sim 6$ years (2250 days); the delayed second peak of $2.57 \times 10^{4} \mathrm{~m}^{3} /$ day at $\sim 21$ years (7640 days) results from the assumed anisotropic coal fracture permeability (Figure 2).

The simulation results for the main-only model are presented as the decrease in matrix pressure at different times $(1,5,15$ and 25 years) in Figure 5 . The decrease in matrix pressure quantifies the volume of reservoir accessed during production and how the drainage volume varies with time. The elliptical drainage area is a result of the higher drainage from the coals in the direction of maximum fracture permeability, while the minor axis of the ellipse is parallel to the direction of the slow fracture permeability. A significant pressure decrease ( $>$ $500 \mathrm{kPa}$ ) occurs after 1 year of production, up to $1200 \mathrm{~m}$ from the center of the wellbore in the direction perpendicular to the lateral and up to $500 \mathrm{~m}$ from the toe and heel of the wellbore in the direction parallel to the lateral. After 5 years of production, drainage occurs up to $2900 \mathrm{~m}$ from the wellbore in the direction perpendicular to the wellbore and $1100 \mathrm{~m}$ in the direction parallel to the wellbore. The decrease in matrix pressure is greater than $1500 \mathrm{kPa}$ over the entire 


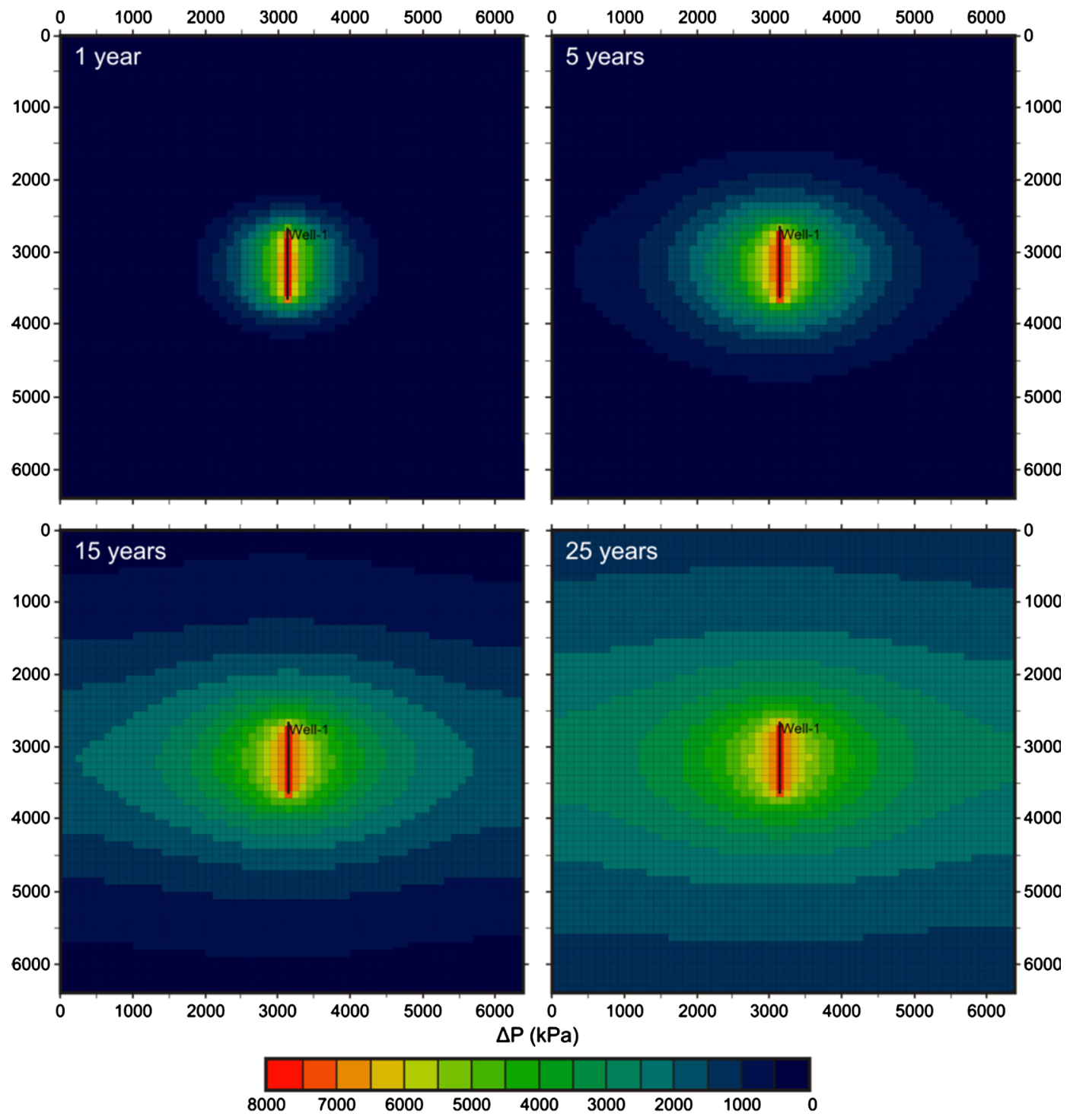

Figure 5. Plots of the change in matrix pressure $(\Delta \mathrm{P}$ in $\mathrm{kPa})$ after $1,5,15$, and 25 years of production for the model with only the main Mannville coal seam (main-only model). Aerial view of the main coal seam at the depth of the horizontal well, shown by black lines. Grid represents the $100 \mathrm{~m}$ model discretization.

width of the model, in the direction perpendicular to the wellbore after 15 years of production and the entire model has experienced a pressure decrease of at least $1000 \mathrm{kPa}$ after 25 years of production.

\subsection{Model with Gas-Bearing Minor Coals and Shales with No Gas}

The addition of minor coal seams to the model, with depths and thicknesses corresponding to those from well 16-10-62-06W5 (Table 1), increases the volume of gas and water stored in the coals by $2.3 \times\left(\right.$ OGIP $=4.05 \times 10^{9} \mathrm{~m}^{3}$; OWIP $3.69 \times 10^{4} \mathrm{~m}^{3}$ ). While $44 \%$ of the fluids are stored within the $4.0 \mathrm{~m}$ thick main coal seam, the top coal seam, U1, which is $0.9 \mathrm{~m}$ thick, contains $9.8 \%$ of the stored fluids, $7.6 \%$ of the fluids are stored in each of the $0.7 \mathrm{~m}$ thick U2 and U3 seams, $20 \%$ is stored in the $1.8 \mathrm{~m}$ thick $\mathrm{L} 1 \mathrm{seam}$, and $11 \%$ is stored in the $1.0 \mathrm{~m}$ 
thick bottom, L2, seam. The addition of interbedded shale layers without stored gas to the model further increases the volume of stored water in the model by 1.7x. The production histories for a model including the gas-bearing minor coal seams and shales with no stored gas (no-shale-gas model) are compared to the histories for the model with only the Mannville coal seam (main-only model) in Figure 3 (blue versus pink curves). The impact of the additional coals and shales on the producibility is predicted to vary over the production history. The ratio of cumulative production for the no-shale-gas model versus the main-only model over the 25-year history is shown in Figure 6 (red curves).

The initial gas and water production rates are the same for the no-shale-gas and main-only models, since the initial drawdown is restricted to the main coal seam near the wellbore. However, the additional water from the minor coals and shales decreases the gas saturation (Figure 4) and thus the relative fracture permeability to gas for the no-shale-gas model compared to the main-only model. The lower relative fracture permeability to gas in the no-shale-gas model restricts the gas recovery from the main coal seam, resulting in slightly lower gas production rates during the first $\sim 50$ days of production. Afterwards, the decreased gas recovery from the main coal seam in the no-shale-gas model is offset by additional gas transported vertically through the interbedded shale layers from the minor coals to the wellbore, which increases the difference in produced gas between the no-shale-gas and main-only models until the end of the 25-year history. The resulting cumulative gas production is slightly (defined in this report as $<1.1 \mathrm{x}$ ) lower during the initial $\sim 4$ months (120 days) of production for the no-shale-gas model than for the main-only model. Whereas, after 25 years of production, $1.4 \times$ more cumulative gas is produced in the no- shale-gas model than the main-only model.

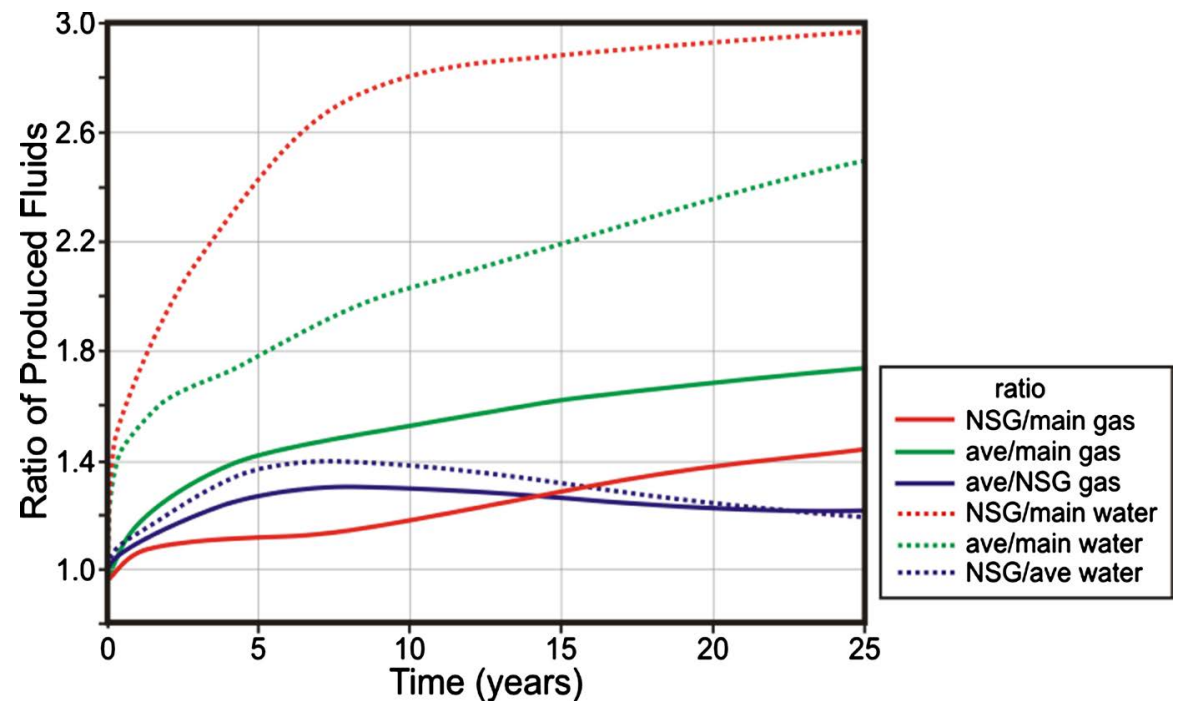

Figure 6. Ratio of cumulative gas production (solids curves) and cumulative water production (dotted curves) predicted from the model with the average coal and shale model parameters (ave), the model with no shale gas (NSG), and the model with only the main coal seam (main). 
The added shale and coal layers also have a great impact on the water production. Although the initial water production rates are the same for the no-shale-gas and main-only models, the added water volume, and the associated increase in the relative fracture permeability to water, results in a higher rate after $\sim 3$ hours of production (blue versus pink curves in Figure 3(d)) and 3.0 $\times$ higher cumulative water production after 25 years than for the main-only model.

\subsubsection{Produced Coal Gas from the Main Mannville Coal Seam}

The cumulative gas recovered and gas recovery rates from the main coal seam over the 25-year history for the main-only and no-shale-gas models are compared in Figure 7 (dashed blue versus pink curves) and the ratio of cumulative gas productions is plotted in Figure 8 (blue curve). The gas recovery from the main coal seam is $1.3 \times$ lower after 1 year of production as a result of the added water from the coals and shales in the no-shale-gas model compared to the main-only model. The decreased recovery from the main coal seam is also apparent by comparing the pressure drawdown predicted in the main coal for the two models. Drainage is predicted up to $2100 \mathrm{~m}$ from the centre of the well in the direction perpendicular to the lateral and $800 \mathrm{~m}$ from the toe and heel of the well in the direction parallel to the lateral for the no-shale-gas model after 5 years of production (Figure 9), compared to $2900 \mathrm{~m}$ and $1100 \mathrm{~m}$ for the main-only model (Figure 5). The difference in gas recovery from the main coal seam between the no-shale-gas and main-only models continues to increase until $\sim 9$ years of production $(1.6 \times)$, after which the difference decreases to a value of $1.4 \times$ after 25 years. The decrease in the difference after 9 years of production is associated with the lower relative fracture permeability to gas resulting from the additional water for the no-shale-gas model, compared to the main-only model, which

(a)

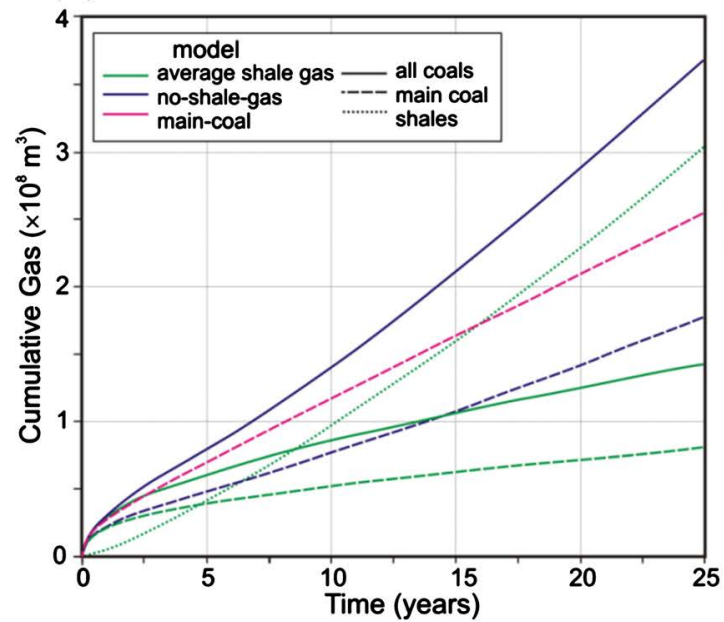

(b)

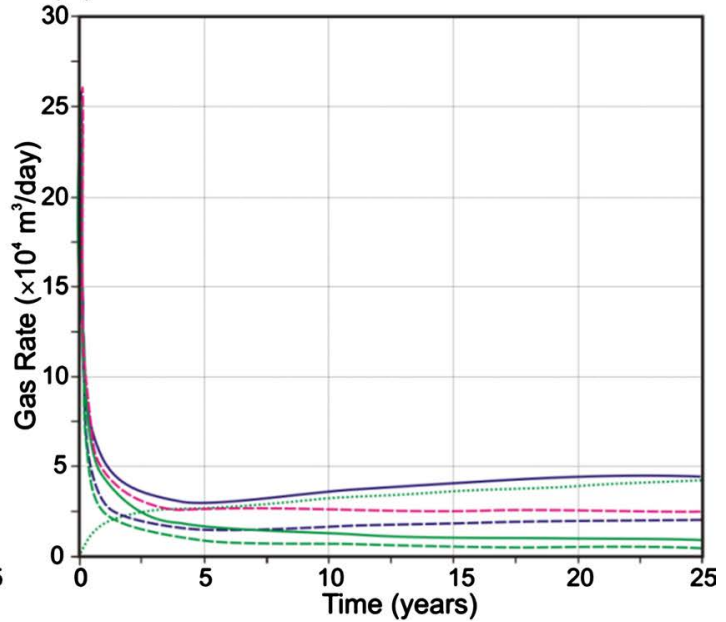

Figure 7. Comparison of cumulative gas recovered (a) and rate of gas recovery (b) from the all the coal seams (solid curves), only the Mannville coal seam (dashed curves), and the shale layers (dotted curves) for a model with gas-bearing coal and shale layers with the average model parameters (average shale gas; green curves), a model with gas-bearing coal layers and shale layers with no gas (no-shale-gas model; blue curves), and a model with only the main Mannville coal seam (main-coal model; pink curves). 


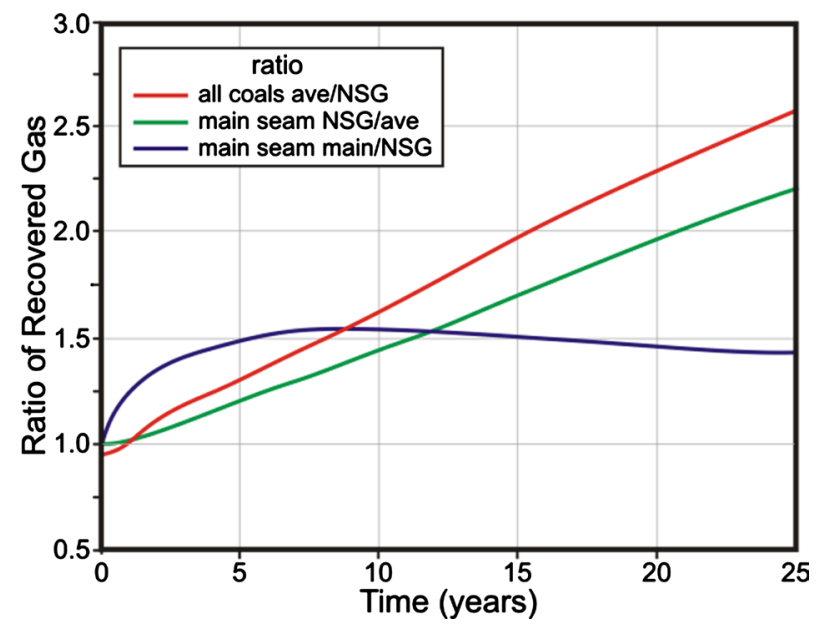

Figure 8. Ratio of recovered gas from the main coal seam between the model with no shale gas (NSG) and the model with shale gas (ave; green curve), the ratio of recovered gas from the main coal seam between the model with only the main coal seam (main) and the model with no shale gas (blue curve), and the ratio of recovered gas from all the coal seams between the model with shale gas and the model with no shale gas (red curve).

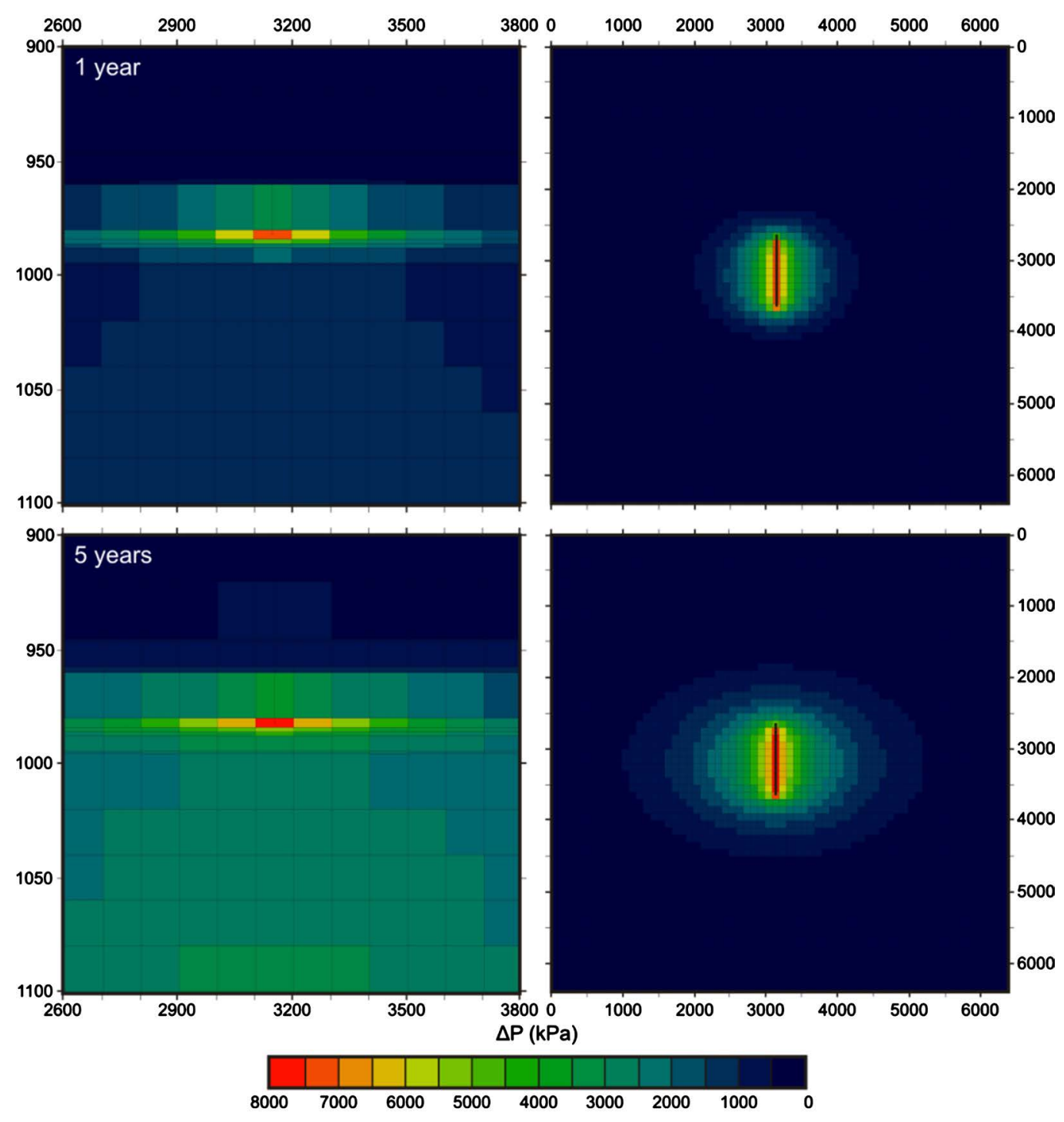




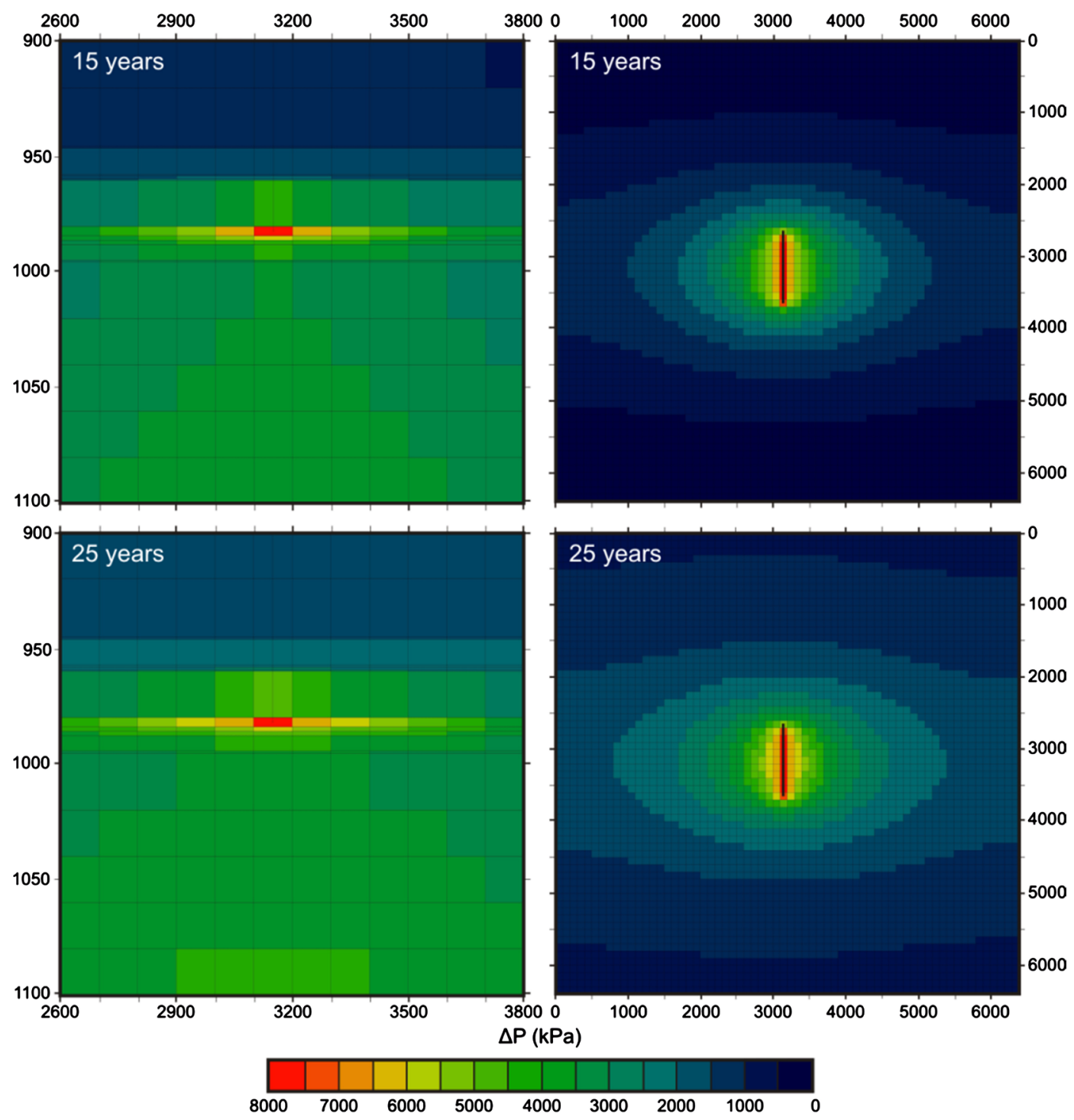

Figure 9. Plots of the change in matrix pressure $(\Delta \mathrm{P}$ in $\mathrm{kPa})$ after $1,5,15$, and 25 years of production for a model with gas-bearing coal layers and shale layers with no gas (no-shale-gas model). Cross-sectional view (left) of a plane perpendicular to the horizontal well through the centre of the well and aerial view (right) of the main coal seam at the depth of the horizontal well, shown by black lines. Grid represents the $100 \mathrm{~m}$ model discretization.

requires a longer period of dewatering and delays the peak gas production rate from $\sim 6$ years (2220 days for main-only model; pink dashed curve in Figure $7(b))$ to $\sim 24$ years (8740 days for no-shale- gas model), which decreases the difference in the gas recovery between the main-only and no-shale-gas models.

\subsubsection{Produced Coal Gas from the Minor Coal Seams}

The peak gas production rate following dewatering for the no-shale-gas model is $1.7 \times$ higher than for the main-only model, as a result of the additional gas-bearing coal seams (blue versus pink curves in Figure 3(b)). While $73 \%$ of the recovered gas after 1 year of production is from the main coal seam for the no-shale-gas model, less than half ( $48 \%$ ) of the cumulative gas recovered after 25 years is from 
the main coal seam ( $60 \%$ after 5 years). The additional gas from the minor coal seams accounts for the increased peak gas production rate. Although the initial production is restricted to the main coal seam, after 1 month of production, seams U3 (contributing to the gas production (Figure 10). Gas from seam U2 (orange curves) is also produced after $\sim 4$ month, while gas from U1 (red curves) is produced after $\sim 4$ years of production.

The two lower coal seams, L1 and L2, which are the deepest, the thickest, and the closest stratigraphically to the horizontal wellbore, provide the most significant contribution to the production (Table 3 ). The proximity of the lower coal seams to the wellbore results in a similar trend in the gas recovery rates as the main coal seam (light blue and blue curves in Figure 10(a) versus blue dashed curve in Figure 7(a)). The contribution of the gas recovered from L1 to the total produced coal gas increases until $\sim 6$ years of production and the contribution

(a)

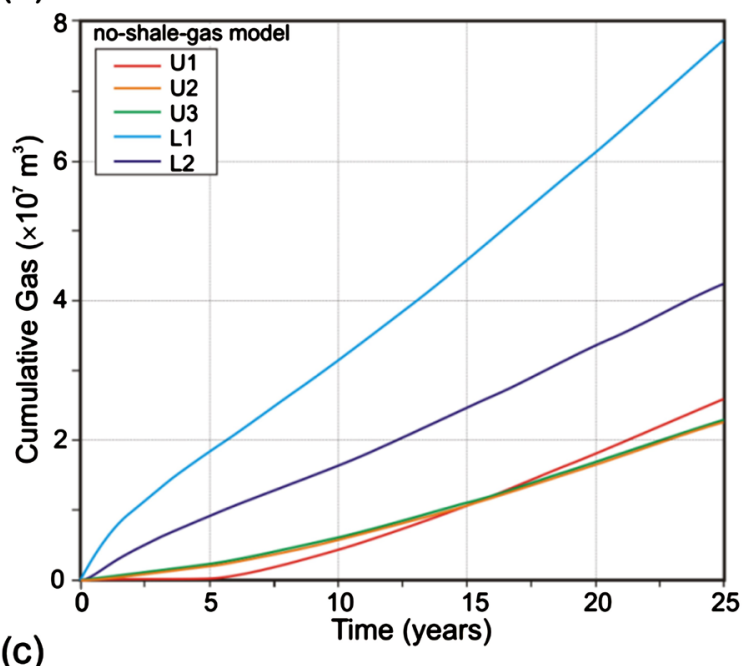

(c)

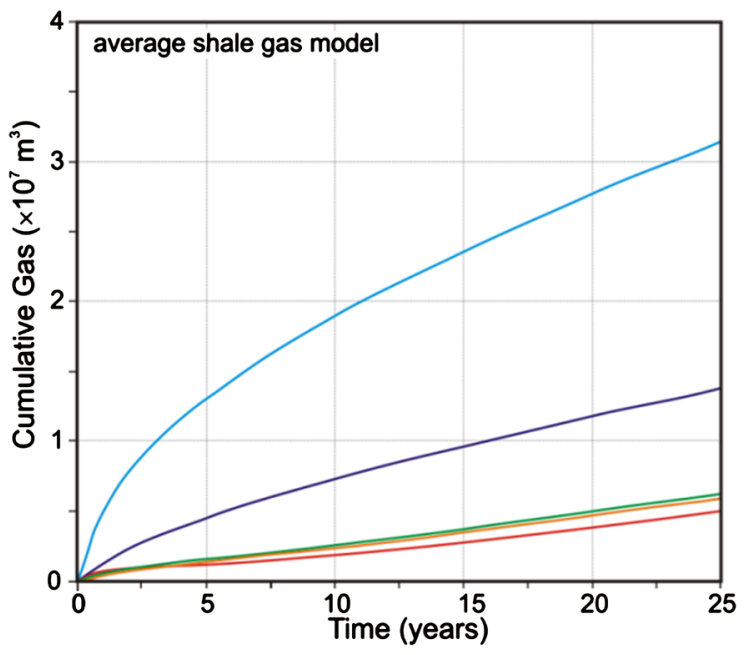

(b)

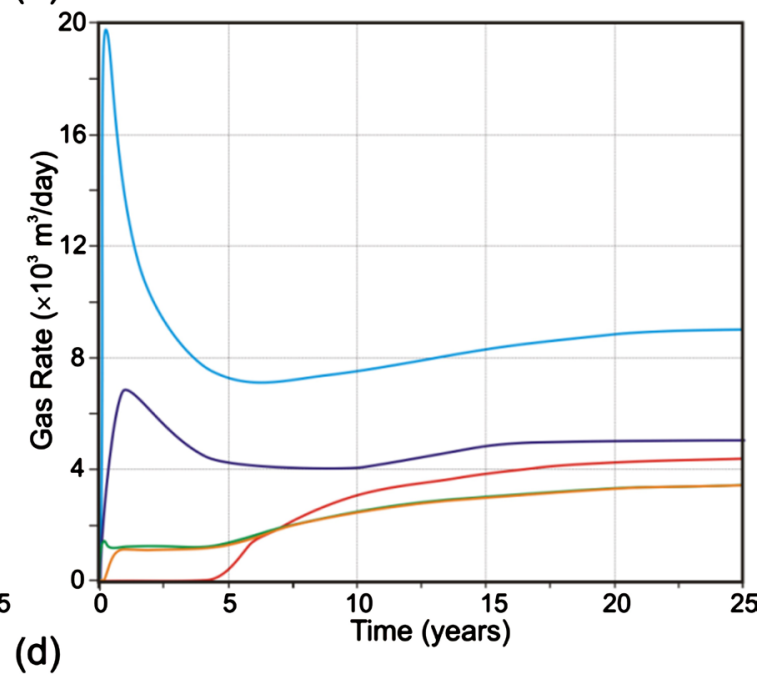

(d)

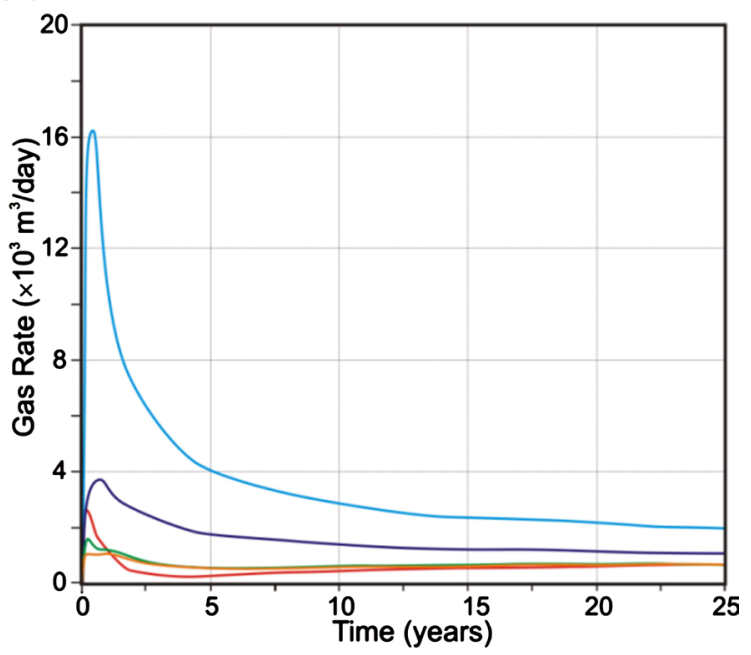

Figure 10. Comparison of cumulative gas recovered (left) and rate of gas recovery (right) from the upper coal seams: U1 (red), U2 (orange), and U3 (green); and the lower coal seams: L1 (light blue) and L2 (blue) for a model with gas-bearing coal layers and shale layers with no gas (no-shale-gas model; Top plots), and a model with gas-bearing coal and shale layers with the average model parameters (average shale-gas model; bottom). 
from the L2 seam increases until $\sim 8$ years of production, after which the contributions slightly decrease due to depletion. In comparison, the gas recovery rates from the upper three seams, which are separated from the wellbore by a $20 \mathrm{~m}$ thick shale interval, are low for the first 5 years yet increase for the entire 25 year production history, resulting in increasing contributions from the upper coal seams over the production history (Figure 10(b) and Table 3). It is also notable that although the uppermost seam, U1, initially contributes less recovered coal gas, after $\sim 16$ years of production, U1 contributes more gas than the deeper, but thinner U2 and U3 seams (Figure 10, Table 3).

\subsection{Model with Gas-Bearing Coals and Gas Bearing Shales with Average Parameter Values}

Including adsorbed gas in the matrix of all the shales in the model, with the average parameters listed in Table 2 (shale-gas model), results in $32 \times$ more gas $\left(\mathrm{OGIP}=1.31 \times 10^{11} \mathrm{~m}^{3}\right)$ and $1.2 \times$ more water $\left(\mathrm{OWIP}=4.43 \times 10^{4}\right)$. The gas stored in the shale layers interbedded between the Mannville coal seams, which accounts for $5.9 \%$ of the additional gas $\left(7.52 \times 10^{9} \mathrm{~m}^{3}\right)$, is $1.9 \times$ greater than the gas stored in the coal seams. Note that the majority of the increase in OGIP results from the thick shale layers over- and under-lying the reservoir. The shale gas stored in the thin interbedded layers results in slower depletion of the coal seams, initially reducing the volume of recovered gas from the coals. The additional gas recovered from the shales more than compensates for the decreased coal gas recovery, resulting in higher cumulative production over the 25 -year history (green versus blue curves in Figure 3(a)). The higher relative permeability to gas due to the added shale gas in the model with shale gas, compared to the no-shale-gas model, results in $1.2 \times$ higher cumulative gas production for the model with shale gas (solid blue curve in Figure 6 ) and $1.2 \times$ lower cumulative water production at the end of the 25 year history (green versus blue curves in Figure 3(c) and dotted blue curve in Figure 6). The addition of the gas-bearing coal and shale layers results in $1.7 \times$ more gas (green versus pink curves in Figure 3(a)

Table 3. Contribution from each coal seam (in \%) to the produced coal gas for different production times.

\begin{tabular}{|c|c|c|c|c|c|c|c|c|c|c|c|c|}
\hline \multirow{2}{*}{$\begin{array}{c}\text { Production } \\
\text { Time }\end{array}$} & \multicolumn{6}{|c|}{ No Shale Gas Model } & \multicolumn{6}{|c|}{ Model with Shale Gas } \\
\hline & U1 & $\mathrm{U} 2$ & U3 & L1 & $\mathrm{L} 2$ & Main & U1 & $\mathrm{U} 2$ & U3 & L1 & L2 & Main \\
\hline 1 month & 0.00 & 0.00 & 0.39 & 4.5 & 0.39 & 95 & 1.1 & 0.25 & 0.89 & 3.5 & 1.3 & 93 \\
\hline 1 year & 0.00 & 0.84 & 1.4 & 19 & 5.7 & 73 & 2.5 & 1.3 & 1.8 & 17 & 4.4 & 73 \\
\hline 5 years & 0.16 & 2.4 & 2.8 & 23 & 11 & 60 & 2.0 & 2.2 & 2.5 & 22 & 7.4 & 64 \\
\hline 10 years & 3.1 & 4.0 & 4.3 & 22 & 12 & 55 & 2.2 & 2.8 & 3.0 & 22 & 8.6 & 61 \\
\hline 15 years & 5.1 & 5.1 & 5.2 & 22 & 12 & 51 & 2.6 & 3.3 & 3.5 & 22 & 9.1 & 59 \\
\hline 20 years & 6.3 & 5.7 & 5.8 & 21 & 12 & 49 & 3.1 & 3.8 & 4.0 & 22 & 9.5 & 57 \\
\hline 25 years & 7.0 & 6.1 & 6.2 & 21 & 12 & 48 & 3.5 & 4.1 & 4.4 & 22 & 10 & 56 \\
\hline
\end{tabular}


and solid green curve in Figure 6) and $2.5 \times$ more water after 25 years of production than when just the main coal seam is considered in the main-only model (1.8× higher after 5 years; green versus pink curves in Figure $3(c)$ and dotted green curve in Figure 6).

\subsubsection{Produced Coal Gas}

Initially, the coal gas recovery is slightly higher for the model with shale gas than the no-shale-gas model. While in both cases the production is restricted to the main coal seam, the presence of the shale gas lowers the impact of the shale water on decreasing the gas saturation and thus on decreasing the relative permeability to gas. The higher relative permeability to gas resulting from the shale gas in the model with shale gas results in a slightly higher coal gas recovery rate for the first $\sim 3$ months of production (solid green versus blue curves in Figure 3(b)) and slightly higher recovered coal gas for the first $\sim 5$ months of production than the no-shale-gas-model (solid green versus blue curves in Figure 3(b) and red curve in Figure 4). After 25 years of production, the coal gas recovery is $2.6 \times$ lower for the shale-gas model than the no-shale-gas model. In comparison to the coal gas recovery rate for the no-shale-gas model, which begins increasing after $\sim 5$ years of production after sufficient dewatering (solid blue curve in Figure $3(b))$, the gas production rate for the shale-gas model continuously decreases following the initial peak (solid green curve in Figure 3(b)). The production of the shale gas suppresses the increase in coal gas recovery following dewatering observed in the no-shale-gas model, which results in the increasing impact of the shale gas on lowering the coal gas recovery with production.

\subsubsection{Produced Shale Gas}

The rate of shale gas recovery exceeds the rate of coal gas recovery after $\sim 2.5$ years of production (green dotted versus dashed curves in Figure 3(b)), resulting in more produced shale gas than coal gas after $\sim 8.5$ years of production (green dotted versus dashed curves in Figure 3(a)). After 5 years of production, $1.5 \times$ more coal gas than shale gas is recovered, while after 15 years, $1.5 \times$ more shale gas than coal gas is recovered, and after 25 years, $2.1 \times$ more shale gas is recovered. The large volume of gas-bearing shale results in an increasing shale gas production rate over the entire production history (green dotted curve in Figure 3(b)). Consequently, the peak total gas production rate, which is reached at 24 years (2220 days) in the no-shale-gas model (blue curve in Figure 3(b)), is delayed until $\sim 70$ years of production in the shale-gas model (green curve in Figure $3(\mathrm{~b})$ ). The delay in peak production rate, due to the large volume of stored shale gas, decreases the impact of the shale gas on the cumulative gas production from $1.3 \times$ after $\sim 8$ years (2970 days) to $1.2 \times$ after $\sim 24$ years of production (solid blue curve in Figure 4 ). After $\sim 24$ years, when the reservoir begins depleting for the no-shale-gas model while the gas production rate is still increasing in the shale-gas model, the impact of the shale gas on improving the cumulative gas production increases again (ex. 1.3× higher after 50 years). 


\subsubsection{Variation in Produced Gas between Coal Seams}

The gas recovery from the main coal seam during the first month of production is approximately the same for the shale-gas model as the no-shale-gas model (difference of 0.14\%; green dashed versus blue dashed curves in Figure 7(a) and green curve in Figure 8); however, while 95\% of the total produced coal gas is recovered from the main coal seam in the no-shale-gas model, $93 \%$ is recovered from the main coal seam in the shale-gas model (Table 3). During the first month of production, before significant shale gas is recovered, the slightly higher cumulative production for the shale-gas model; therefore, is due to the greater contribution from the minor coal seams (resulting in the lower contribution from the main coal seam). Similarly to the no-shale-gas model, L1 in the shale-gas model contributes the largest volume of recovered gas compared to the other minor coal seams. The gas recovery from L1 and the resulting contribution to the total produced coal gas; however, is lower during the first month of production for the shale-gas model compared to the no-shale-gas model (light blue curves in Figure 10(d) versus Figure 10(b) and light blue curve in Figure 11). The gas recoveries from the other four seams, which are farther from the wellbore, are higher during the initial month for the shale-gas model than the no-shale-gas model (Figure 10(d) versus Figure 10(b)), accounting for the slightly higher initial gas production for shale-gas model, as well as the lower initial contribution of the recovered gas from the main coal seam to the total produced coal gas (Table 3). The higher initial recovery from the coal seams farther from the wellbore for the shale-gas model than the no-shale-gas model is a consequence of the higher relative permeability to gas, which results in the preferential production of the coal gas in the shale-gas model over the shale water in the no-shale-gas model.

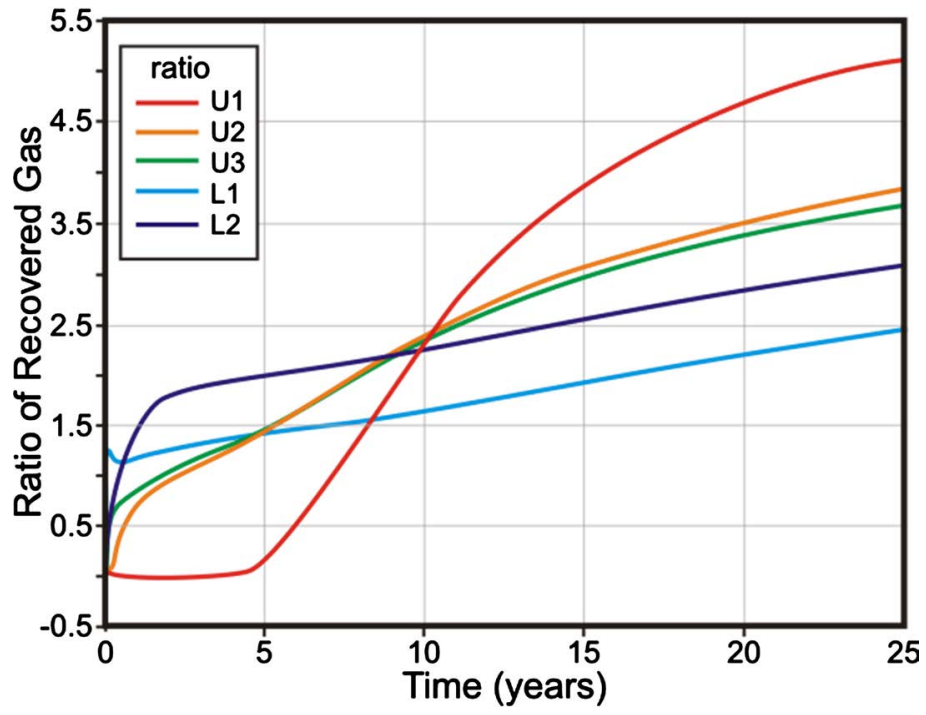

Figure 11. Ratio of recovered gas from the upper coal seams: U1 (red curve), U2 (orange curve), and U3 (green curve); and the lower coal seams: L1 (light blue curve) and L2 (dark blue curve) between the model with no shale gas (no-shale-gas model) and the model with shale gas (average shale-gas model). 
The impact of the shale gas on decreasing the recovery from the main coal seam results in $2.2 \times$ less recovered gas from the main coal seam after 25 years of production (green curve in Figure 8). Similarly to the no-shale-gas model, the gas recovery rate for the main coal seam, and the two lower minor coal seams, follow the general trend of the total gas production rate. The added shale gas; however, results in a slightly earlier peak recovery rate for the lower coals, from $\sim 3$ months for L1 (light blue curve) and $\sim 1$ year for L2 (blue curve) in the no-shale-gas model (Figure 10(b)) to $\sim 2.5$ months and $\sim 9$ months in the with shale-gas model (Figure 10(d)). The initial peak recovery rate from L1 is also $1.2 \times$ lower for the shale-gas model than the no-shale-gas model as a result of the added shale gas. The lower initial peak rate for the shale-gas model, results in $1.2 \times$ less recovered gas from L1 after 1 year of production than for the no-shalegas model (light blue curve in Figure 11). The impact of the shale gas on lowering the gas recovery from L1 increases to $2.5 \times$ after 25 years. The L2 seam, which is separated from the base of $\mathrm{L} 1$ by a $6.7 \mathrm{~m}$ shale interval, predicts higher gas recovery for the shale-gas model than the no-shale-gas model during the first $\sim 6.5$ months of production (blue curves in Figure 10 and blue curve in Figure 11). The peak gas recovery rate from L2 $(\sim 1$ year for no-shale- gas model and $\sim 9$ months for shale-gas model); however, is $1.8 \times$ lower for the shale-gas model compared to the no-shale-gas model. After 25 years of production, the impact of the shale gas results in $3.1 \times$ less gas recovered from L2 for the shale-gas model.

In contrast to the main and lower coal seams, the gas recovery rates for the upper coal seams rebound following dewatering and increase until the end of the production history (Figure 10(d)). The upper two coal seams, U1 (red curves in Figure 10(c) and Figure 10(d)) and U2 (orange curves in Figure 10(c) and Figure 10(d)), contribute to the early production for the shale-gas model, which differs from the no-shale-gas model (red and orange curves in Figure 10(a) and Figure 10(b)), as a result of the higher relative permeability to gas, due to the shale gas. The higher relative permeability to gas in the shale-gas model results in higher gas recovery from the upper seams than the no-shale-gas model for several years of production (Figure 10 and Figure 11). The shale gas in the shale-gas model results in higher gas recovery after $\sim 1.5$ years of production from the deepest of the upper coal seams, U3 (green curves), higher gas recovery after $\sim 2.5$ years from U2 (orange curves), and after $\sim 7.5$ years from U1 (red curves). The smaller increase in gas recovery rate from the coals, following dewatering, for the shale-gas model than the no-shale-gas model, results in significantly lower gas recovery from the upper coal seams during the last half of the production history. After 25 years of production, the shale gas results in $3.7 \times$ less recovered gas from U3, 3.8 $\times$ less gas from U2, and $5.1 \times$ less gas from U1 for the shale-gas model than the no-shale-gas model (Figure 10 and Figure 11).

The initially recovered gas from $\mathrm{U} 1$ and its contribution to the total produced coal gas is greater than from U2 and U3 for the shale-gas model, while after $\sim 3$ years of production the recovered gas from $\mathrm{U} 1$ is lower than from $\mathrm{U} 2$ and $\mathrm{U} 3$. 
However, for the no-shale-gas model, the initial recovered gas from U1 is lower than $\mathrm{U} 2$ and $\mathrm{U} 3$ and is greater than $\mathrm{U} 2$ and $\mathrm{U} 3$ after $\sim 17$ years of production. The higher relative permeability to gas resulting from the addition of the shale gas to the shale-gas model transports the easily accessible gas stored in U1 to the wellbore within the first few years of production, while the dewatering in the no-shale-gas model delays the recovery of gas from $\mathrm{U} 1$.

\subsubsection{Drainage Volume}

During the first year of production, the drawdown predicted for the shale-gas model is mainly restricted to the coal seams; $87 \%$ of the produced gas is from the coal layers. After 1 year of production, significant drawdown ( $>500 \mathrm{kPa}$ ) occurs up to $1000 \mathrm{~m}$ from the center of the well in the direction perpendicular to the lateral and $400 \mathrm{~m}$ from the toe and heel of the well in the direction parallel to the lateral (Figure 12), slightly less than the drawdown predicted for the no-shale-gas model (1100 $\mathrm{m}$ and $400 \mathrm{~m}$; Figure 9). After 25 years, significant drawdown occurs the

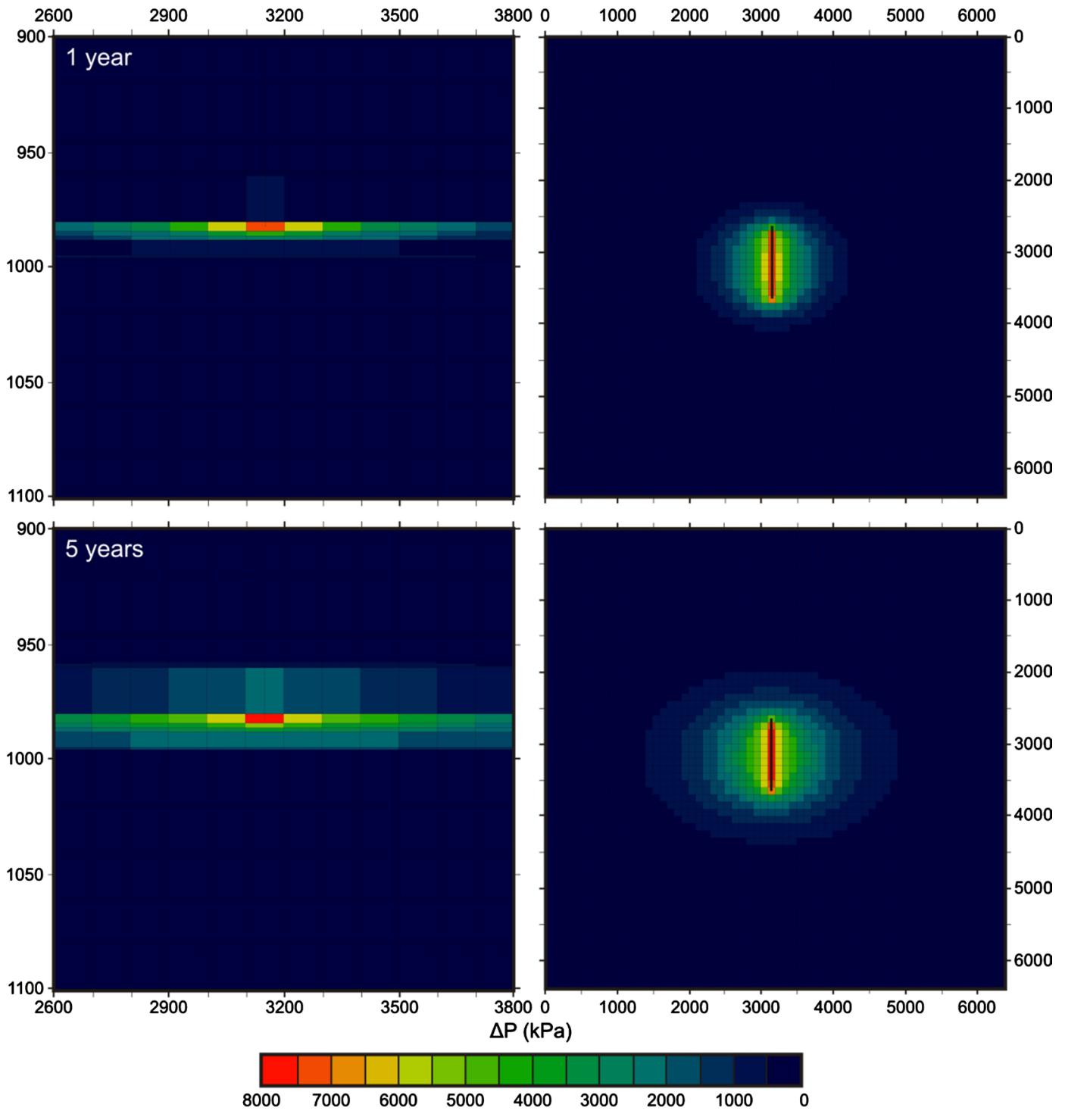




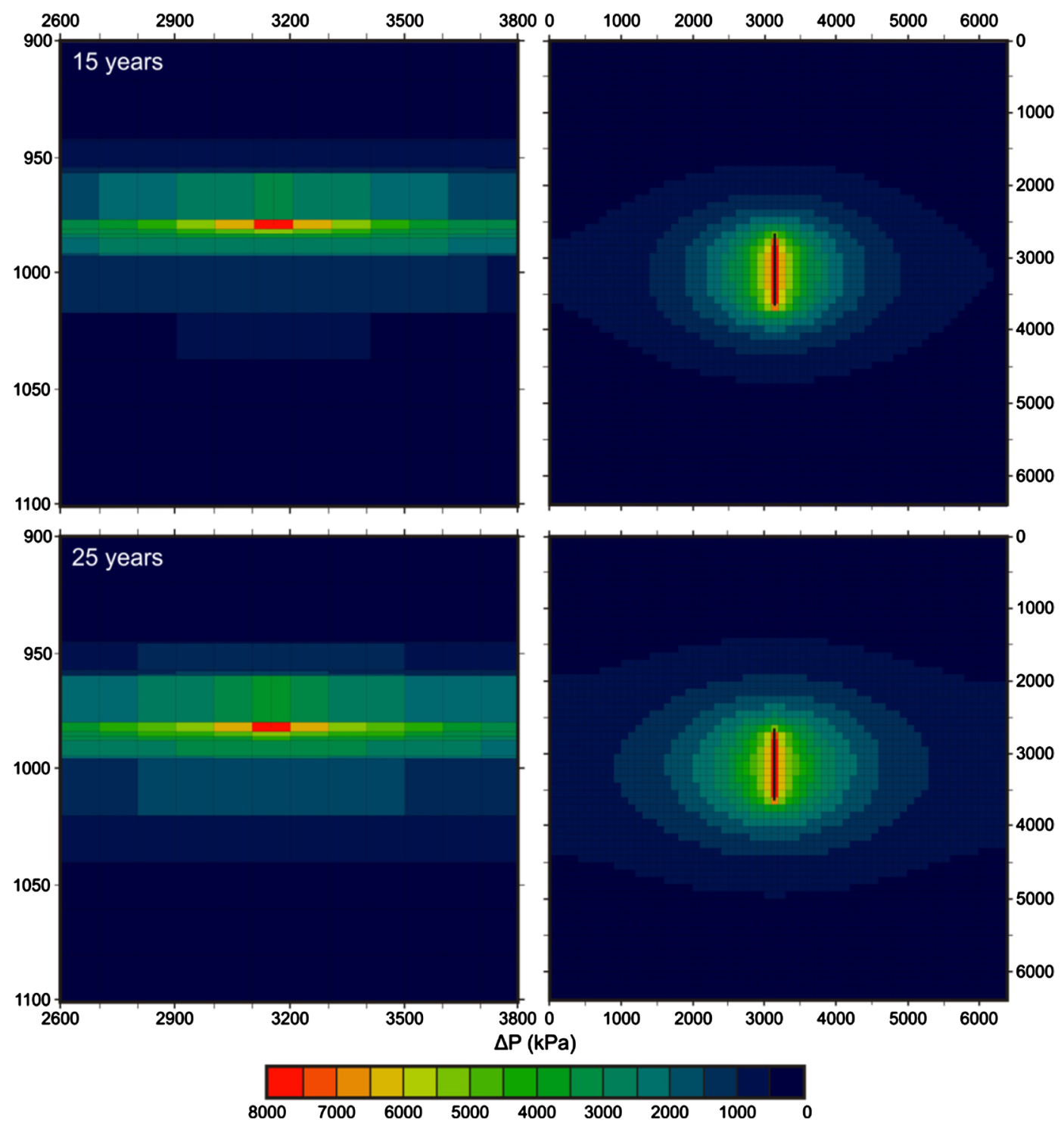

Figure 12. Plots of the change in matrix pressure $(\Delta \mathrm{P}$ in $\mathrm{kPa})$ after $1,5,15$, and 25 years of production for the model with gas-bearing coal and shale layers with the average model parameters (shale-gas model). Cross-sectional view (left) of a plane perpendicular to the horizontal well through the centre of the well and aerial view (right) of the main coal seam at the depth of the horizontal well, shown by black lines. Grid represents the $100 \mathrm{~m}$ model discretization

entire $3200 \mathrm{~m}$ width of the model perpendicular to the lateral and up to $1200 \mathrm{~m}$ from the toe and heel parallel to the lateral. The decreased drainage from the main coal, following the initial production period, which results from the addition of shale gas in the shale-gas model, is apparent from a comparison of the change in matrix pressure after 25 years for the no-shale-gas model (Figure 9), which shows a pressure drawdown greater than $900 \mathrm{kPa}$ over the entire model.

Although the majority of the gas production is from the coal layers, the interbedded shale layers, S3, S4, and S5 predict a significant pressure drawdown after the first year of production (Figure 12). The thin shale, S4, directly underlying the main coal seam contributes most significantly to the production, with a 
maximum decrease in matrix pressure of $4300 \mathrm{kPa}$. For comparison, the maximum decrease in matrix pressure for $\mathrm{S} 5$ is $730 \mathrm{kPa}$. As apparent from the large pressure drawdown in the shale layers, the recovered shale gas greatly increases following the initial production period (a maximum change in matrix pressure of $2200 \mathrm{kPa}$ in S3, $5100 \mathrm{kPa}$ in S4, and $2300 \mathrm{kPa}$ in S5 after 5 years) and after 5 years of production, $40 \%$ of the produced gas is from the shale layers. After 25 years of production, $68 \%$ of the produced gas originated from the shales with significant drainage predicted in all interbedded shale layers, as well as in the 40 $\mathrm{m}$ of shale below the reservoir (i.e. underlying L2; Figure 12).

\subsubsection{Water Production}

While the initial water production rates are the same for the no-shale-gas and shale-gas models, the greater dewatering required to increase the relative permeability to gas in the no-shale-gas model increases the difference in cumulative water production to $1.4 \times$ after 7.5 years ( 2760 days) of production (green versus blue curves in Figure 3(c) and blue dotted curve in Figure 6). The shorter period of dewatering required for the no-shale-gas model, more rapidly depletes the accessible water and after $\sim 13.5$ years (4899 days) of production, the water production rate in the no-shale-gas model is lower than the rate in the shale-gas model (blue versus green curves in Figure 3(d)). The difference in cumulative water production between the average shale gas and no-shale-gas models thus decreases over the second half of the production history to $1.2 \times$ after 25 years. The shale-gas model predicts that the added shale and coal layers result in $2.5 \times$ more water after 25 years of production for the shale-gas model compared to the main-only model (green versus pink curves in Figure 3(c) and green dotted curve in Figure 6).

\section{Discussion}

For a $6400 \times 6400 \mathrm{~m}$ model containing only the main Mannville coal seam, 2.56 $\times 10^{8} \mathrm{~m}^{3}$ of gas is recovered after 25 years of production, $14 \%$ of the original stored gas, from a single $1000 \mathrm{~m}$ horizontal lateral, oriented perpendicular to the coal fracture permeability anisotropy $\left(\mathrm{k}_{\mathrm{H}}=3 \mathrm{k}_{\mathrm{h}}\right)$ (pink curve in Figure $3(\mathrm{a})$ ). Including the gas-bearing minor coal seams in the model, with interbedded shale layers containing no gas, increases the cumulative gas production by $1.4 \times$ after 25 years of production (blue versus pink curves in Figure 3(a)). The addition of absorbed gas to the shale layers in the model further increases the cumulative gas production a maximum of $1.3 \times$ after $\sim 8$ years of production and by $1.2 \times$ after 25 years of production (green versus blue solid curves in Figure 3(a)). Including the gas in both the coal seams and the shales results in a maximum of $1.7 \times$ higher cumulative gas production after 25 years than when only the main Mannville coal seam is included (green versus pink solid curves in Figure 3(a)).

The additional gas from the minor coal seams and water from the shales decreases the gas recovered from the main coal seam by a maximum of $1.6 \times$ after $\sim 9$ years of production and $1.4 \times$ after 25 years of production when no shale gas 
is considered compared to a model with only the main coal seam. Including the shale gas further decreases the gas recovery from the main coal seam by a maximum of $2.2 \times$ after 25 years of production. The impact of the shale gas is greater on decreasing recovery of gas from coal seams farther from the wellbore $(2.5 \times$ for L1, 3.1× for L2, 3.7× for U3, 3.8× for U2, and 5.1× for U1 after 25 years). While, the recovered gas from the main and L1 seams are lower, due to the addition of shale gas, over the 25-year history, the recovered gas from the other four minor coal seams is initially greater. The gas recoveries are greater and are higher for longer periods of production for coal seams farther from the wellbore $(\sim 8$ months of production for L2, $\sim 3$ years for U3, $\sim 4$ years for U2, and $\sim 8$ years for U1).

The total produced gas recovered from the coal seams is greater until $\sim 5$ months of production as a result of the higher recovery of gas from L2 and the upper seams, due to the shale gas. The impact of the shale gas on reducing the produced coal gas increases over the production history resulting in $2.6 \times$ less produced coal gas after 25 years of production (1.3× after 5 years). After 25 years of production, over half (56\%) of the produced coal gas is recovered from the main coal seam, while almost a quarter (22\%) is recovered from the L1 seam, which is the thickest and nearest minor coal seam to the wellbore, when shale gas is included in the model. The three upper seams are separated by $20 \mathrm{~m}$ or greater thick shale layers and thus contribute a smaller percentage to the produced coal gas (L2 contributes 10\%, U3 4.4\%, U2 4.1\%, and U1 3.5\% after 25 years). The recovered shale gas exceeds the recovered coal gas after $\sim 8.5$ years of production, resulting in $2.1 \times$ less recovered coal gas than shale gas after 25 years (green dotted versus dashed curves in Figure 3(a)). Significant drainage is predicted from all the interbedded shale layers, as well as the $40 \mathrm{~m}$ of shale underlying the reservoir, with the greatest drawdown predicted in the thin shale directly underlying the main coal seam.

The cumulative water production is a maximum of 3.0 $\times$ higher after 25 years of production, due to the addition of the minor coal seams and shale layers with no gas to a model with only the main coal seam (blue versus pink curves in Figure $3(\mathrm{~b})$ ). Including shale gas in the model predicts a maximum of $1.4 \times$ lower cumulative water after $\sim 7.5$ years and $1.2 \times$ less at the end of the 25 year history (green versus blue curves in Figure $3(\mathrm{~b})$ ), which results in a maximum of $2.5 \times$ higher cumulative water production after 25 years than when only the main coal seam is considered (green versus pink curves in Figure 3(b)).

\section{Conclusions}

The results from our numerical simulations quantify the contribution of the minor coal seams and organic rich shales interbedded with and over- and under-lying the main Mannville coal seam, in which a lateral well is normally drilled and completed. Including the minor coal seams of the Mannville Group in a numerical simulation of a $1000 \mathrm{~m}$ lateral well completed in the main (i.e. 
thickest) coal seam, predicts 1.4 times more gas production after 25 years than when only the main seam is considered. Including absorbed gas to the interbedded and over- and under-lying shale layers in the model further increases the cumulative gas production a maximum of $1.3 \times$ after $\sim 8$ years of production and by $1.2 \times$ after 25 years of production. The predicted water production is increased 3.0× after 25 years when the minor coal seams are included, while including the shale gas decreases the water production by a maximum of $1.4 \times$ after $\sim 7.5$ years and $1.2 \times$ after 25 years, resulting in $2.5 \times$ higher cumulative water production after 25 years than when only the main coal seam is considered.

The modelling predicts that adding the minor coals seams decreases the gas recovered from the main coal seam a maximum of $1.6 \times$ after $\sim 9$ years and $1.4 \times$ after 25 years of production and including shale gas further decreases the gas recovered by a maximum of $2.2 \times$ after 25 years of production. The impact of the shale gas is greater on decreasing the recovery of gas from coal seams farther from the wellbore. While the recovered gas the main seam and the L1 seam, which is the thickest and nearest minor seam to the horizontal wellbore, are decreased, the recovered gas from the other four minor coal seams is initially increased. The gas recoveries are greater and are higher for longer periods of production for coal seams farther from the wellbore. The initially higher gas recovery from the other four minor seams results in a higher total gas recovery from the coal seams until $\sim 5$ months of production. The impact of the shale gas on reducing the produced coal gas then increases over the production history resulting in $2.6 \times$ less produced coal gas after 25 years of production $(1.3 \times$ after 5 years). After 25 years of production, over half (56\%) of the produced coal gas is recovered from the main coal seam, while almost a quarter (22\%) is recovered from the L1 seam.

The recovered shale gas exceeds the recovered coal gas after $\sim 8.5$ years of production, resulting in $2.1 \times$ less recovered coal gas than shale gas after 25 years. Significant drainage is predicted from all the interbedded shale layers, as well as the $40 \mathrm{~m}$ of shale underlying the reservoir, with the greatest drawdown predicted in the thin shale directly underlying the main coal seam.

The results from the numerical simulations provide insights that are not intuitive or otherwise predictable in developing complex reservoirs, such as present in the coal measures of the Upper Mannville Group. Although my results are specifically for the Mannville producing fairway, undoubtedly the production from minor coal seams and interbedded gas shales should be considered in other producing and potential coal gas reservoirs to identify higher producible reserves and optimize drilling and completion strategies.

\section{Acknowledgements}

This study was made possible through access to data and money from Trident Exploration Corp. and the authors would like to thank Virgil Todea. We are also thankful to CMG for their ongoing support. 


\section{Conflicts of Interest}

The authors declare no conflicts of interest regarding the publication of this paper.

\section{References}

[1] Bustin, A.M.M. and Bustin, R.M. (2016) Total Gas-in-Place Gas Composition and Reservoir Properties of Coal of the Mannville Coal Measures, Central Alberta. International Journal of Coal Geology, 153, 127-143.

https://doi.org/10.1016/j.coal.2015.11.011

[2] Bustin, A.M.M. and Bustin, R.M. (2016) Contribution of Non-Coal Facies to the Total Gas-in-Place in Mannville Coal Measures, Central Alberta. International Journal of Coal Geology, 144-145, 69-81. https://doi.org/10.1016/j.coal.2015.12.002

[3] Gu, F. and Chalaturnyk, R.J. (2005) Analysis of Coalbed Methane Production by Reservoir and Geomechanical Coupling Simulation. Journal of Canadian Petroleum Technology, 44, 33-42. https://doi.org/10.2118/05-10-03

[4] Wong, S., Law, D., Deng, X., Robinson, J., Kadatz, B., Gunter, W.D., et al. (2007) Enhanced Coalbed Methane and $\mathrm{CO}_{2}$ Storage in Anthracitic Coals-Micro-Pilot Test at South Qinshui, Shanxi, China. International Journal of Greenhouse Gas Control, 1, 215-222. https://doi.org/10.1016/S1750-5836(06)00005-3

[5] Maricic, N., Mohaghegh, S.D. and Artun, E. (2008) A Parametric study on the Benefits of Drilling Horizontal and Multilateral Wells in Coalbed Methane Reservoirs. Society of Petroleum Engineers Reservoir Evaluation and Engineering, 11, 976-983. https://doi.org/10.2118/96018-PA

[6] Mora, C.A. and Wattattenbarger, R.A. (2009) Comparison of Computation Methods for CBM Performance. Journal of Canadian Petroleum Technology, 48, 42-48. https://doi.org/10.2118/09-04-42

[7] Ren, B., Sun, Y. and Bryant, S. (2014) Maximizing Local Capillary Trapping during CO2 Injection. Energy Procedia, 63, 5562-5576.

https://doi.org/10.1016/j.egypro.2014.11.590

[8] Liu, P. and Zhang, X. (2015) Enhanced Oil Recovery by $\mathrm{CO}_{2}-\mathrm{CH}_{4}$ Flooding in Low Permeability and Rhythmic Hydrocarbon Reservoir. International Journal of Hydrogen Energy, 40, 12849-12853. https://doi.org/10.1016/j.ijhydene.2015.07.013

[9] Gentzis, T. and Bolen, D. (2008) The Use of Numerical Simulation in Predicting Coalbed Methane Producibility from the Gates Coals, Alberta Inner Foothills, Canada: Comparison with Mannville Coal CBM Production in the Alberta Syncline. International Journal of Coal Geology, 74, 215-236. https://doi.org/10.1016/j.coal.2007.12.003

[10] Bustin, A.M.M. and Bustin, R.M. (2011) Horseshoe Canyon and Belly River Coal Measures, South Central Alberta: Part 2 Modeling Reservoir Properties and Producible Gas. Journal of Canadian Petroleum Geology, 59, 235-260. https://doi.org/10.2113/gscpgbull.59.3.235

[11] Berhane, H. (2009) CBM Potential of the Alberta Plains-Net Thickness of the Mannville Coal Zone (GIS Dataset) Alberta Geological Survey, Digital Data 2009-0043.

[12] Taylor, M., Hancock, B. and Bustin, R.M. (2008) Coalbed Methane Development in Canada, Challenges and Opportunities. International Geological Congress, Oslo, 6-14 August 2008. 
[13] Berhane, H. (2009) CBM Potential of the Alberta Plains-Depth to Top of the Mannville Coal Zone (GIS Dataset) Alberta Geological Survey, Digital Data 2009-0049.

[14] Hayes, B.J.R., Christopher, J.E., Rosenthal, L., Los, G., McKercher, B., Minken, D. and Smith, D.G. (1994) Cretaceous Mannville Group of the Western Canada Sedimentary Basin. Geological Atlas of the Western Canada Sedimentary Basin, 4, 317-334.

[15] Langenberg, C.W., Rottenfusser, B.A. and Richardson, R.J.H. (1997) Coal and Coalbed Methane in the Mannville Group and Its Equivalents, Alberta. Petroleum Geology of the Cretaceous Mannville Group, Western Canada. CSPG Memoir, 18, 475-486.

[16] ERCB (Energy Resources Conservation Board) (2006) ST98-2006: Alberta’s Energy Reserves 2005 and Supply/Demand Outlook 2006-2015. https://www.aer.ca/documents/sts/ST98/ST98-2006.pdf

[17] Beaton, A., Langenberg, W. and Pană, C. (2006) Coalbed Methane Resources and Reservoir Characteristics from the Alberta Plains, Canada. International Journal of Coal Geology, 65, 93-113. https://doi.org/10.1016/j.coal.2005.04.013

[18] Rottenfusser, B. (2002) Regional Evaluation of the Coalbed Methane Potential in the Plains and Foothills of Alberta, Stratigraphy and Rank Study. Alberta Energy and Utilities Board, Alberta Geological Survey, Alberta.

[19] Berhane, H. (2009) CBM Potential of the Alberta Plains-Calculated Gas Content of the Mannville Coal Zone (GIS Dataset) Geospatial Data Presentation Form: Vector Digital Data, Alberta Geological Survey, Digital Data 2009-0069.

[20] Beaton, A.P. (2003) Production Potential of Coalbed Methane Resources in Alberta. Earth Sciences Report, 3.

[21] Gentzis, T., Goodarzi, F. Cheung, F.K. and Laggoun-Defare, F. (2008) Coalbed Methane Producibility form the Mannville Coals in Alberta, Canada: A Comparison of Two Areas. International Journal of Coal Geology, 24, 237-249. https://doi.org/10.1016/j.coal.2008.01.004

[22] Bearinger, D. and Majcher, M. (2010) Controls on Mannville Coalbed Methane Production in Fort Assiniboine, Alberta. Canadian Unconventional Resources and International Petroleum Conference, Calgary, 19-21 October, SPE-137924-MS. https://doi.org/10.2118/137924-MS

[23] Hyland, F., Palmai, F.J., Abaco, C., Ionkina, N., Yu, M. and Cox, W. (2010) Mannville CBM: Integrated Approach in the Mikwan Area. Canadian Unconventional Resources and International Petroleum Conference, Calgary, 19-21 October, SPE-138114-MS. https://doi.org/10.2118/138114-MS

[24] Bustin, A.M.M. and Bustin, R.M. (2017) Impact of Reservoir Properties on the Production of the Mannville Coal Measures, South Central Alberta from a Numerical Modelling Parametric Analysis. Engineering, 9, 291-327.

https://doi.org/10.4236/eng.2017.93016 